\title{
Desenvolvimento Financeiro e Crescimento Econômico: Teoria e Evidência Empírica para as Unidades Federativas do Brasil $(1995-2004)^{*}$
}

\section{Financial Development and Economic Growth: Theory and Empirical Evidence for the Brazilian States (1995-2004)}

\author{
Fabrício José Missio** \\ Frederico Gonzaga Jayme Jr* * * \\ Ana Maria Hermeto Camilo de Oliveira****
}

\begin{abstract}
Resumo: O objetivo deste trabalho é analisar teórica e empiricamente a relação entre desenvolvimento financeiro e crescimento econômico para as unidades federativas do Brasil. Para tanto, realiza-se um exercício econométrico com o auxílio da técnica de regressão quantílica para o período de 1995 a 2004, o que permite um mapeamento mais completo do impacto gerado pelas medidas de desenvolvimento financeiro utilizadas sobre a variável resposta. Para mensurar o desenvolvimento do sistema financeiro foram seguidas duas estratégias, baseadas na construção de indicadores que captam dimensões como o tamanho do setor, o nível de atividade, o desenvolvimento e a eficiência do sistema financeiro. Além disso, a análise emprega um indicador da preferência pela liquidez do público e dos bancos para captar o argumento pós-keynesiano. As evidências encontradas sugerem, em geral, uma relação positiva entre desenvolvimento do sistema financeiro e crescimento econômico e a possibilidade de efeitos regionais distintos.
\end{abstract}

Palavras-chave: Desenvolvimento financeiro. Crescimento econômico. Regressão quantílica.

Abstract: This paper aims at analyzing the relationship between economic growth and financial development across Brazilian States. For both, an empirical exercise was undertaken using data for the Brazilian states. We estimate quantile regression in order to show the impact of financial development on the dependent variable (the Gross State Product, GSP) for the period 1995 to 2004. To measure the development of the financial system followed two strategies, based on the development of indicators that capture three dimensions of the financial system: the size of the sector, the level of activity and

\footnotetext{
* Os autores agradecem os comentários de Anderson Cavalcante e dos pareceristas anônimos. Evidentemente, erros e omissões remanescentes são de responsabilidade dos autores.

* $\quad$ Professor do curso de Economia da Universidade Estadual de Mato Grosso do Sul (UEMS). E-mail: fabriciomissio@gmail.com

*** Professor do Centro de Desenvolvimento e Planejamento Regional (Cedeplar) da Faculdade de Ciências Econômicas da Universidade Federal de Minas Gerais (UFMG). Este autor agradece o financiamento do CNPq e da Fapemig. E-mail: gonzaga@cedeplar.ufmg.br

**** Professora adjunta do Centro de Desenvolvimento e Planejamento Regional (Cedeplar) da Faculdade de Ciências Econômicas da Universidade Federal de Minas Gerais (UFMG). Bolsista do CNPq. E-mail: ahermeto@cedeplar.ufmg.br
} 
efficiency. Furthermore, the analysis employs an indicator of liquidity preference of banks and the public to analyze the post keynesian argument. Empirical results suggest a positive relationship between development of the financial development and economic growth and the possibility of distinct regional effects.

Keywords: Financial development. Economic growth. Quantile regression.

JEL Classification: O10; G20; O42; C31.

\section{1 lntrodução}

As interpretações teóricas sobre a influência do sistema financeiro para o crescimento são variadas e, em geral, controversas. Por um lado, a abordagem convencional, entendida como aquela que trata o mercado financeiro como locus da intermediação de capital (enquanto recursos reais) entre poupadores e investidores, entende o sistema financeiro como um intermediário de recursos cuja existência é justificada principalmente por seu papel de diversificar as oportunidades de alocação dos recursos, minimizar os custos de agenciamento e mitigar os efeitos dos custos de informação e de transação no processo de intermediação. Por outro lado, a abordagem heterodoxa, sobretudo de orientação keynesiana, admite que a moeda e as instituições financeiras têm um papel crucial no funcionamento e na dinâmica de uma economia empresarial. Ademais, reconhece a importância do setor financeiro ao entender como se dá a fragilidade do sistema capitalista. ${ }^{1}$

Nessa abordagem, grande parte da importância do sistema financeiro está relacionada à decisão de investir a partir do descasamento entre o financiamento e o retorno do investimento. ${ }^{2}$ Isso porque os agentes tendem a tomar seus recursos junto ao sistema financeiro por períodos curtos de tempo a uma dada taxa de juros. No entanto, como o investimento é uma atividade que oferece retornos de longo prazo, esses agentes têm que buscar formas de refinanciamento ou de rolar suas dívidas. Portanto, cabe às instituições e aos mercados financeiros o papel de diversificar os ativos ofertados aos poupadores, bem como o de administrar as estruturas passivas e ativas com prazos de maturação distintos.

Em um cenário em que as condições econômicas tenham se deteriorado e/ ou a intermediação financeira seja pouco desenvolvida, o processo de refinanciamento das dívidas ou de alongamento desses empréstimos (mesmo por meio de

1 Segundo essa abordagem, os mercados financeiros têm um importante, mas, ao mesmo tempo, ambíguo papel de dar suporte ao crescimento sustentado. Por um lado, eles podem ajudar a transformar as maturidades das firmas, ao fazer a mediação entre os demandantes de títulos e as firmas desejosas de consolidar suas obrigações de curto prazo em dívidas de longo prazo e, por outro, eles podem ser uma fonte de instabilidade criada a partir da ação de especuladores (PAULA, 2013).

2 O argumento original de Schumpeter (1911) destaca o papel do financiamento na dinâmica das economias capitalistas, uma vez que dele depende o processo de inovações. 
taxas mais elevadas) pode ser inviabilizado, o que desestimula o investimento. Assim, quando não existem mecanismos que garantam esse processo, apenas o animal spirits pode justificar o ato de investir. Por outro lado, quando o sistema financeiro é bem desenvolvido, há maior diversificação de riscos e maior oferta de crédito, o que afeta as expectativas dos empresários em relação à possibilidade de refinanciamento dos investimentos, criando um ambiente positivo para a sua realização.

Do ponto de vista empírico, alguns trabalhos buscam quantificar essa relação no plano internacional, nacional ou regional. Dentro da literatura convencional, destacam-se os trabalhos de King e Levine (1993a,b,c), Rousseau e Wachtel (1998), Levine (1997), Arestis e Demetriades (1998) e Beck, Levine e Loayza (2000), enquanto, na abordagem heterodoxa, Crocco, Cavalcante e Barra (2005), Crocco, Figueiredo e Santos (2010), Crocco, Santos e Amaral (2010) e Cavalcante (2011), entre outros. Em geral, as evidências encontradas corroboram a hipótese de que o desenvolvimento do sistema financeiro é um importante determinante da taxa de crescimento econômico.

O debate na literatura recai ainda sobre qual sistema financeiro é o mais apropriado para o crescimento: se market-centered ou bank-centered. Essa discussão não será retomada aqui, e o conceito de desenvolvimento do sistema financeiro utilizado está associado ao conceito de desenvolvimento do sistema bancário. Por sua vez, este se refere à capacidade de as instituições financeiras de um país ou região colocarem à disposição dos agentes econômicos serviços que facilitem e intensifiquem suas transações econômicas.

Nesse contexto, o objetivo deste artigo é analisar, com base nos dados dos 26 estados brasileiros e do Distrito Federal, a relação entre desenvolvimento financeiro e crescimento econômico, bem como a possibilidade de que essa relação seja distinta entre as unidades de análise quando controlada pelos diferentes níveis de renda. A justificativa para a sua realização está baseada no fato de que os estudos empíricos para o Brasil, conforme apresentados na revisão bibliográfica realizada, apontam que o desenvolvimento do sistema financeiro é um importante componente capaz de determinar o crescimento econômico. Não obstante, o número de estudos é limitado, e é praticamente nulo o interesse nos trabalhos econométricos por questões regionais. Considerando que o Brasil é um país continental com profundas heterogeneidades econômicas e sociais, admite-se que essa é uma dimensão importante que deve ser levada em consideração, em especial porque existe a possibilidade de que a influência do desenvolvimento financeiro seja desigual à da perspectiva regional. Mais ainda, é possível que o desenvolvimento financeiro tenha efeitos contraditórios dependendo do grau de desenvolvimento de determinada região. 
Um dos poucos estudos que levam em consideração essa dimensão regional é o de Galeano e Feijó (2011). Com dados relativos às unidades federativas do Brasil e utilizando o método de estimação com dados em painel para o período 2004-2008, as autoras mostram que o efeito do crescimento do crédito sobre o crescimento do PIB foi positivo e significativo a $5 \%$ em todas as regiões. Ademais, os resultados mostram que esse efeito varia de região para região. Contudo, o período analisado é bastante controverso e as estimativas são realizadas para as cinco grandes regiões (Sul, Sudeste, Norte, Nordeste e Centro-Oeste). Nesse caso, além do reduzido número de observações, o método não permite identificar se ocorrem mudanças de sinal do parâmetro de interesse ao longo da distribuição.

Sendo assim, para cumprir com os objetivos, realiza-se uma série de exercícios econométricos utilizando como método a regressão quantílica, o que permite um mapeamento mais completo do impacto gerado pelas medidas de desenvolvimento financeiro utilizadas sobre a variável resposta (PIB estadual). O período analisado (1995-2004) leva em consideração a disponibilidade dos dados e, especialmente, o fato de constituir um período de relativa estabilidade da economia brasileira, sobretudo no que se refere às variáveis utilizadas no exercício empírico. Ademais, optou-se por não incluir dados relativos aos anos mais recentes, pois os períodos pré e pós-crise podem ser considerados distintos e, assim, podem acabar direcionando a análise. Por fim, ressalta-se que este estudo se enquadra na abordagem em que o desenvolvimento financeiro afeta diretamente o crescimento econômico.

O artigo desenvolve-se em quatro seções, além desta introdução e das considerações finais. A segunda seção apresenta uma breve revisão dos argumentos teóricos sobre a relação entre desenvolvimento do sistema financeiro e crescimento a partir da abordagem tradicional e da abordagem pós-keynesiana; a terceira seção apresenta uma revisão da evidência empírica existente, com ênfase na questão da causalidade; a quarta seção apresenta a metodologia e a base de dados a ser empregadas nos exercícios econométricos; e a quinta seção apresenta os resultados alcançados.

\section{Fundamentos Teóricos}

\subsection{Abordagem Convencional}

Há algum consenso na literatura tradicional de crescimento sobre a importância de variáveis reais para a explicação do desenvolvimento econômico. Assim, fatores tecnológicos, estoque de capital (físico e humano) e a relação de preferências entre lazer e trabalho constituem o ponto central e o foco de análises dessas teorias (SOLOW, 1956; ROMER, 1986; LUCAS, 1988). Atualmente, novas interpretações sobre o processo de crescimento econômico têm surgido, com ênfase em 
novos aspectos capazes de explicar "o resíduo de Solow". Embora esses modelos busquem formas alternativas capazes de contribuir para entender as causas fundamentais do crescimento, deve-se destacar que o arcabouço teórico sobre o qual são construídos remete à estrutura formal dos modelos de crescimento exógenos à la Solow e/ou aos modelos de crescimento endógeno à la Romer (1986), Lucas (1988) e Rebelo (1991). ${ }^{3}$

A dificuldade oriunda do modelo de Solow (1956) é que este oferece poucas possibilidades analíticas, uma vez que, no longo prazo, o crescimento depende, em última instância, das taxas de crescimento populacional e de progresso tecnológico, variáveis exógenas no modelo. As novas teorias de crescimento econômico e seus novos tratamentos para o desenvolvimento tecnológico e capital humano resolveram, em parte, alguns dos problemas anteriores, tornando possível que uma maior variedade de políticas afete o crescimento de longo prazo. Como exemplo, observa-se que diversos estudos empíricos têm sido realizados como versões "aumentadas" da teoria tradicional, tal como a extensão proposta originalmente por Mankiw, Romer e Weil (1992), incluindo, para tanto, diferentes proxies que buscam captar a influência do capital humano, da tecnologia, das preferências e de outras variáveis tidas como importantes na explicação do desempenho econômico de longo prazo.

Nesse contexto, mais importante do que essa abordagem para o crescimento de longo prazo foi o reconhecimento de que existem outros fatores responsáveis pela sua determinação. Recentemente, ampliou-se o escopo de análise ao serem retomadas algumas causas fundamentais responsáveis pelo crescimento econômico, que já estavam presentes nas abordagens de Marx (1968), Furtado (1966, 1959), Hirschman (1982, 1961), entre outros. Nesse caso, as instituições passam a constituir a causa fundamental, ainda que o crescimento econômico possa ser resultado de um processo complementar entre diferentes forças. Se tecnologia, capital físico e capital humano são importantes para entender as diferenças entre a riqueza das nações, então por que as sociedades não melhoram esses fatores? Simplesmente porque as análises baseadas apenas nesses fatores estão incompletas, dado que esses fatores são apenas causas eminentes (proximate causes) do crescimento. ${ }^{4}$

Na literatura neoclássica do crescimento econômico, estudos recentes têm reforçado também a importância do lado financeiro como explicação para o processo de crescimento. Esses estudos remontam os trabalhos seminais de Gurley e Shaw (1955) e Goldsmith (1969) e buscam explicar o fato estilizado de forte correlação entre crescimento econômico e variáveis financeiras. Convém destacar que, embora a relação entre essas duas dimensões econômicas seja explorada há

\footnotetext{
3 Para uma apresentação completa dessa classe de modelos, ver Barro e Sala-i-martin (2004) e Acemoglu (2009).

4 Ver Acemoglu, Johnson e Robinson (2005).
} 
tempos por outras correntes de pensamento, é recente o entendimento da ortodoxia quanto à importância do sistema financeiro como fonte de crescimento econômico. Segundo esses autores, a importância desse sistema reside não só na capacidade de aumentar a captação de recursos, mas, principalmente, na habilidade em alterar suas alocações, podendo ter, dessa maneira, forte impacto sobre o crescimento tecnológico e a produtividade (BECK; LEVINE; LOAYZA, 2000).

Todavia, mesmo dentro dessa abordagem, a relação entre desenvolvimento do sistema financeiro e crescimento é controversa. Existe um razoável número de desenvolvimentos formais que explicitam essa relação, ${ }^{5}$ ainda que do ponto de vista empírico o número de trabalhos recentes tenha aumentado significativamente. Seguindo Matos (2002) e Graff (2002), entre outros, é possível afirmar que, de uma perspectiva da história do pensamento econômico, existem quatro visões teóricas principais sobre o tema: de um lado, a linha teórica principal e mais tradicional, que está amparada em um conjunto extenso de modelos que postulam a hipótese de que o desenvolvimento financeiro afeta diretamente o crescimento econômico; e, de outro lado, as demais visões, que oscilam entre as postulações de determinação conjunta à relação de causalidade inversa (em que o crescimento determina o desenvolvimento financeiro) e à ausência de relação. ${ }^{6}$

Os autores que postulam uma relação de causalidade inversa argumentam que o crescimento da atividade bancária é neutro, pois resulta naturalmente do aumento geral das transações de troca que decorrem do crescimento econômico ou do desenvolvimento industrial. Ou seja, crescimento econômico ou desenvolvimento industrial causam o desenvolvimento do sistema financeiro. O argumento é o de que o crescimento afeta a configuração do sistema financeiro, pois este implica aumentos da demanda por serviços desse setor advindos da dinâmica da atividade econômica. ${ }^{7}$ Nesse caso, a hipótese a ser testada é que o crescimento econômico é a variável exógena (enquanto desenvolvimento financeiro é a variável endógena), e o resultado esperado em temos econométricos é que esse coeficiente seja positivo e estatisticamente significativo. Ademais, como mencionado, espera-se uma causalidade no sentido do crescimento para o desenvolvimento financeiro.

A linha de argumentação que postula a relação conjunta entre desenvolvimento financeiro e crescimento econômico baseia-se no pressuposto de que a dinâmica da atividade econômica gera os meios para formar uma intermediação financeira promotora de crescimento, enquanto esta, ao intensificar a alocação de capital, acelera o crescimento. Ou seja, o aumento da eficiência do setor financeiro leva ao crescimento do produto que, por seu turno, gera demandas adicionais

$5 \quad$ Ver, por exemplo, Fry (1995).

6 A abordagem que defende a ausência de relação está associada ao teorema de Modigliani e Miller (1958) sobre a irrelevância das políticas e estruturas financeiras das empresas, o que implica que, em condições de competição perfeita, pouco importa a estrutura do financiamento.

7

Sobre essa literatura ver, entre outros, Shaw (1973). 
por depósitos e serviços financeiros. Ademais, como destaca Levine (1997), o sistema financeiro pode ser moldado por avanços não financeiros, como mudanças nas telecomunicações, na informática, nas políticas do setor não financeiro, nas instituições e no próprio crescimento econômico, na medida em que essas mudanças influenciam a qualidade dos serviços e a estrutura do sistema financeiro. Assim, desenvolvimento do sistema financeiro e crescimento econômico podem ser entendidos como processos que são determinados conjuntamente (MATOS, 2002).

A abordagem que defende a existência de uma relação positiva tem como argumento central que o sistema financeiro é eficiente na conexão entre a alocação de poupança e a demanda de recursos por partes dos empresários. Ou seja, existem dois grandes canais através dos quais os bancos exercem sua influência sobre o processo de crescimento econômico. O primeiro é por meio da redução dos custos de transação e da diversificação de riscos, de tal forma que o sistema financeiro permite a mobilização de poupança para financiar os investimentos. $\mathrm{O}$ segundo enfatiza a alocação de crédito e, assim, o papel dos bancos é identificar os empresários mais capazes de introduzir inovações, proporcionando-lhes poder de compra.

\subsection{A Abordagem Keynesiana}

Apesar de Keynes não ter dedicado nenhum capítulo da "Teoria Geral do Emprego, do Juro e da Moeda", publicada em 1936, para analisar especificamente o papel dos bancos, a obra contribui fundamentalmente para entendimento da sua influência no processo de desenvolvimento.

Como mencionado anteriormente, a importância do sistema financeiro emerge pelo fato de o investimento ser uma atividade que oferece retornos de longo prazo, de modo que os agentes têm de buscar formas de refinanciamento ou de rolagem de suas dívidas.

Mais especificamente, a contribuição de Keynes pode ser entendida a partir do debate sobre a relação poupança/investimento e a problemática do financiamento. O debate sobre a irrelevância da poupança para o financiamento do investimento ocorre no âmbito do circuito finance-investimento-poupança-funding. Esse processo ocorre em duas etapas, sendo que a primeira está associada ao investimento planejado, ou seja, aquele que ainda não foi efetivamente realizado. Nesse caso, esse investimento corresponde ao crédito de curto prazo demandado pelas firmas para financiar a produção de bens de capital no intervalo de tempo entre a decisão de investir e sua implementação (finance motive). Observa-se que a poupança ainda não foi criada. A segunda etapa relaciona-se ao investimento efetivamente realizado, ao qual corresponde uma poupança agregada que surge via multiplicador de gastos. 
Nessa interpretação, o finance não advém das poupanças, sejam elas ex ante ou ex post, mas de um fundo rotativo de ativos líquidos (moeda e crédito bancário) gerenciado pelos bancos. Nesse caso, o crédito associado ao finance encontra sua oferta nesse fundo. Ele é usado para estimular a atividade na indústria de bens de investimento, gerando, nesse processo, uma renda através do multiplicador keynesiano. Ao final do processo, após a operação do multiplicador, a poupança resultante da despesa de investimento é usada para transformar a dívida de curto prazo dos investidores junto ao sistema bancário em passivo de longo prazo. $\mathrm{O}$ funding corresponde a esse processo de "consolidar" a dívida de curto prazo, isto é, transformá-la numa relação de longo prazo através da emissão de ações e de títulos (RESENDE, 2007). Em suma, dois pontos devem ser destacados: a) poupança e financiamento da despesa do investimento não se confundem; e b) embora as poupanças existam sempre em magnitude suficientemente para as operações de funding, há um intervalo mínimo de tempo no qual estarão forçosamente sob a forma de liquidez imediata, isto é, sob a forma de moeda, portanto indisponíveis para o funding. Nesse intervalo, a realização de novos investimentos dependerá da disposição dos bancos em tornar-se menos líquidos. Se não o desejarem, a demanda adicional de funding elevará as taxas de juros, desincentivando o investimento. A restrição ao investimento será, portanto, de liquidez, não de poupança.

Nesse contexto, observa-se que são os bancos, não os poupadores, quem desempenham um papel crucial na transição de um nível de atividade baixo para outro mais alto. Se os bancos se recusarem a expandir suas operações ativas, a elevação das taxas de juros induzida pelo aumento de pedidos de finance terá o efeito de desencorajar alguns projetos de investimento, cuja taxa de retorno não é suficientemente alta a ponto de serem atrativos num contexto em que a taxa de juros é mais elevada.

A teoria da preferência pela liquidez complementa a análise e consiste na afirmação de que a taxa de juros a qualquer momento é "[...] a recompensa por abrir-se mão da liquidez, uma medida do desejo daqueles que possuem moeda de abrir mão do seu controle sobre ela" (Keynes, 1973: 167). Nesse caso, o autor observou que um excesso de demanda por moeda poderia elevar as taxas de juros "se as preferências pela liquidez do público (separada daquela dos investidores empresariais) e dos bancos não mudarem (KEYNES, 1973, p. 667, grifo nosso). Ou seja, a taxa de juros é determinada pela preferência pela liquidez e pela oferta de moeda, esta influenciada pela política monetária e pelas estratégias de crédito dos bancos.

Assim, a decisão de investir e o investimento efetivamente realizado estão associados ao conceito de preferência pela liquidez e este, por sua vez, ao conceito de incerteza. Mais especificamente, o investimento é sensível ao grau de incerteza e às expectativas a ele associadas, que, por seu turno, dependem, entre outros 
fatores, das condições de finance e de funding do sistema. Essas condições são influenciadas pela preferência pela liquidez do público (PLP) e dos bancos (PLB).

Apesar dos insights presentes na teoria keynesiana, o impulso para o desenvolvimento da literatura heterodoxa sobre o papel dos bancos advém, sobretudo, da insatisfação do pensamento pós-keynesiano com a teoria ortodoxa da firma bancária, em grande parte porque entendem que a manutenção de ativos líquidos na carteira se deve não apenas à segurança - como defendido na abordagem clássica da intermediação bancária -, mas à conveniência e à flexibilidade, cujo rendimento implícito é o prêmio de liquidez.

Ademais, a análise se distingue por abordar tanto o lado da oferta quanto o lado da demanda no mercado de crédito. A distinção está no fato de que, para essa abordagem, a oferta e a demanda de crédito são interdependentes e afetadas pela preferência pela liquidez, vinculada às expectativas que os agentes formam em um ambiente de incerteza. Assim, do ponto de vista dos bancos, a preferência pela liquidez afetará negativamente a sua disposição em emprestar, caso possuam expectativas pessimistas ou pouco confiáveis a respeito, enquanto, pelo lado da demanda por crédito, afetará suas respectivas definições de portfólio. Isto é, quanto maior a preferência pela liquidez, maiores as posições em ativos líquidos desses agentes e menores as suas demanda por crédito.

Nesse contexto, os bancos são vistos também como agentes ativos que administram dinamicamente os dois lados de seus balanços. Do ponto de vista do seu passivo, isso significa que eles não tomam este como dado, na medida em que procuram influenciar as preferências dos depositantes através do gerenciamento das obrigações e da introdução de inovações financeiras:

Como qualquer firma capitalista, bancos têm como principal objetivo a obtenção de lucro na forma monetária. Para tanto, tomam suas decisões de portfólio orientadas pela perspectiva por maiores lucros, levando em conta sua preferência pela liquidez e suas avaliações sobre a riqueza financeira, em condições de incerteza que caracteriza uma economia monetária da produção. Deste modo, os bancos enfrentam a escolha básica entre satisfazer os compromissos de empréstimo ou preservar a flexibilidade para maximizar a liquidez do seu ativo em um ambiente adverso (PAULA, 1999, p. 3).

Em síntese, na alternativa pós-keynesiana o papel do sistema financeiro é mais complexo e essencial que o de um simples intermediador entre investidores e poupadores. Primeiro, especialmente em situações de crescimento, a participação ativa do sistema bancário é essencial na determinação do volume de financiamento do investimento. Segundo, a poupança, embora criada como subproduto do processo multiplicador do investimento, pode desempenhar um papel fundamen- 
tal na consolidação financeira do passivo de curto prazo das empresas inversoras e dos bancos (STUDART, 1993).

Um exemplo da aplicação do conceito de preferência pela liquidez dos bancos (PLB) e das implicações daí resultantes pode ser encontrado na análise espacial (DOW, 1992). Nesse caso, procura-se demonstrar a possibilidade de que, entre determinadas regiões e/ou países com igual base monetária, possa ocorrer diferenças nos multiplicadores monetários, sendo estes multiplicadores mais elevados onde as expectativas sobre os preços locais dos ativos forem mais otimistas, onde os mercados locais desses ativos forem mais líquidos e onde o grau de desenvolvimento financeiro for maior.

Segundo Barra e Crocco (2004, p. 389), é possível inserir esse pensamento na explicação das diferenças regionais de desenvolvimento:

Dois casos extremos de regiões diferentes em suas características são considerados: uma região central e uma periférica. O centro seria uma região próspera, com mercados ativos e sofisticação financeira. A periferia seria uma economia estagnada, com tênues mercados e um menor grau de sofisticação financeira. Como resultado destas características, a preferência pela liquidez seria maior na periferia, a liquidez de qualquer ativo seria maior no centro do que na periferia e, no longo prazo, o multiplicador bancário seria maior no centro. Da mesma forma, a contextualidade espacial permite que o agente possa manter, simultaneamente, ativos de economias de várias regiões, implicando não só endogeneização espacial da base monetária, como também reforçando o caráter distinto das ofertas de moeda regionais.

\section{Evidência Empírica}

Antes de se analisar a evidência empírica, importa salientar que o conceito de desenvolvimento do sistema financeiro utilizado ao longo do trabalho está associado à ideia de desenvolvimento do sistema bancário. Assim, a revisão aqui realizada faz referência aos trabalhos que se utilizam, em geral, desse mesmo conceito. Entende-se, portanto, que ao mesmo tempo que a inclusão adicional de trabalhos que testam hipóteses diferentes associados a outros conceitos de desenvolvimento financeiro se revela complementar, ela é excessivamente extensa e passível de incorporar dificuldades adicionais. ${ }^{8}$

Um dos principais trabalhos empíricos que retomam a relação entre desenvolvimento financeiro e crescimento econômico é o de Levine (1997). O autor testa empiricamente um modelo em que o crescimento (variável dependente) é medido pelo PIB per capita e o desenvolvimento financeiro por quatro indicadores alternativos: a) passivo líquido do sistema financeiro como proporção do PIB;

$8 \quad$ Ver, por exemplo, Gelb (1989), Arestis, Chortareas e Desli (2006), La Porta et al. (1998), entre outros. 
b) razão entre crédito bancário e crédito bancário + ativos internos do banco central; c) crédito ao setor privado como proporção do crédito doméstico total; e d) crédito ao setor privado como proporção do PIB. Adicionalmente, utilizam-se algumas variáveis de controle (número de matrículas na escola secundária em 1960, razão consumo governamental/PIB, inflação em 1960 e grau de abertura da economia). O estudo foi realizado para uma amostra de 77 países, e os resultados obtidos indicam que o desenvolvimento financeiro em termos de passivos líquidos/PIB em 1960 é diretamente relacionado à renda per capita média do período. ${ }^{9}$

Em um segundo trabalho, Levine (1999) examina se componentes exógenos do desenvolvimento financeiro, tais como as características dos ambientes legais e de regulação, são positivamente associados aos diferenciais de crescimento entre países. As conclusões indicam que esses componentes são positivamente associados ao crescimento econômico.

Todavia, no que concerne à relação entre intermediários financeiros e crescimento econômico, os trabalhos mais conclusivos no plano internacional são os de King e Levine (1993a, 1993b, 1993c). Os autores realizam exercícios econométricos para uma amostra de 80 países no período entre 1960 e 1989, utilizando como variáveis dependentes o crescimento do PIB per capita, o crescimento da produtividade e a acumulação de capital per capita, e como variáveis explicativas, medidas de desenvolvimento da intermediação financeira. Além disso, o exercício leva em consideração alguns controles, como a taxa de inflação, a abertura econômica, a política fiscal e a escolaridade da população. As evidências encontradas sugerem que: o desenvolvimento da intermediação financeira está positivamente correlacionado com as diferentes medidas de crescimento econômico e o nível de desenvolvimento da intermediação financeira, em 1960, é um fator relevante para explicar as taxas de crescimento econômico no período 1960-1989.

Dentro dessa mesma perspectiva, Beck, Levine e Loayza (2000) propõem um experimento econométrico mais cuidadoso do que aquele empregado por King e Levine (1993a, 1993b). Nesse caso, os autores utilizam um conjunto de dados socioeconômicos e financeiros de 63 países entre 1960 e 1995 para avaliar a importância do sistema financeiro na determinação da poupança, do capital e da produtividade. Os resultados mostram uma relação robusta e positiva entre crescimento e os indicadores financeiros empregados, corroborando, assim, a evidência supracitada.

Silva e Porto Jr. (2006) analisam a existência de uma relação positiva entre desenvolvimento financeiro e crescimento econômico nos diversos quantis da distribuição condicional da variável resposta (taxa de crescimento real do PIB per

$9 \quad$ O autor afirma que "Although the conclusions must be stated hesitantly and with ample qualifications, the preponderance of theoretical reasoning and empirical evidence suggests a positive, first-order relationship between financial development and economic growth" (LEVINE, 1997, p. 688). 
capita). O trabalho utiliza uma amostra de 77 países para o período de 1980 a 1992, e as estimativas produzidas por regressão quantílica permitem concluir que: a) há uma relação positiva entre desenvolvimento financeiro e crescimento econômico; b) mesmo controlando por características cross-country, os parâmetros estimados se mantêm positivos; e c) quanto maior o quantil (isto é, maior a taxa de crescimento econômico), maior é a contribuição do sistema financeiro para o crescimento.

No caso específico do Brasil, a literatura que relaciona desenvolvimento do sistema financeiro e crescimento econômico tem despertado interesse recente, embora os estudos ainda sejam incipientes. Um dos trabalhos pioneiros que capta essa relação é de Arraes e Teles (2000), no qual são estimados dois modelos: o primeiro com o propósito de avaliar os efeitos temporários e permanentes decorrentes de mudanças no comportamento de diversas variáveis sobre o produto per capita (juntamente com variáveis como progresso tecnológico, capital humano, tamanho do governo, abertura econômica, infraestrutura de transportes, distribuição de renda, foi incluído o desenvolvimento financeiro); e o segundo, a partir de um sistema de equações com o objetivo de amenizar o problema da endogeneidade entre as variáveis produto per capita, capital físico, capital humano e tecnologia. Os resultados apontam que, no primeiro modelo, em geral a relação entre desenvolvimento financeiro e produto per capita foi positiva e significativa no longo prazo. No segundo, embora a variável que representa o sistema financeiro não entre diretamente na equação que determina o PIB per capita, observa-se que o desenvolvimento financeiro, via progresso tecnológico, é integrado à atividade produtiva.

Monte e Távora Júnior (2000) analisam os impactos sobre o PIB dos estados nordestinos dos financiamentos dedicados a essa região pelos seguintes órgãos de fomento: a) Banco do Nordeste/Fundo Constitucional de Financiamento do Nordeste; b) Superintendência de Desenvolvimento do Nordeste/Fundo de Investimento do Nordeste; e c) Banco Nacional de Desenvolvimento Econômico e Social. O resultado do estudo mostra que os desembolsos de todos esses órgãos apresentam uma relação positiva com o produto, sugerindo a relevância das três fontes de recursos para o crescimento econômico regional.

O estudo de Triner (1996) examina os vínculos entre os bancos, crescimento econômico e industrialização, estimando, para isso, equações de demanda de depósitos bancários, como função da taxa do produto real e dos preços, assim como equações de oferta determinada através da variação do produto e dos saldos reais de encaixe para o período de 1906 a 1930. Conclui-se que o sistema bancário estava, então, fortemente integrado à economia produtiva e mais diretamente relacionado ao crescimento industrial do que ao da agricultura (MATTOS, 2002). 
A influência do setor financeiro sobre a economia brasileira é observada, também, de forma inovadora no estudo de Araújo e Dias (2006), no qual é desenvolvido um modelo teórico que estabelece a interação entre quatro agentes - governo, firmas, setor bancário e famílias -, o que tornou o setor financeiro da economia endógeno e dependente, por um lado das decisões das famílias a respeito de quanto manter nos bancos sob a forma de depósitos e, por outro, da política de reservas bancárias a ser adotada pelo governo. Os resultados econométricos mostram que para a economia brasileira, no período de 1980-2003, uma elevação na variável exógena (reservas bancárias) ocasionou reduções permanentes na taxa de crescimento da economia.

Os estudos que trabalham com dados desagregados por municípios também tendem a confirmar a relação positiva apontada pela literatura. Kroth e Dias (2006) estimam um painel dinâmico para analisar a contribuição do crédito bancário e do capital humano na determinação do crescimento econômico dos municípios brasileiros. O trabalho engloba a análise de 3.211 municípios brasileiros que apresentaram operações de crédito no período de 1999 a 2003, e os principais resultados mostram que operações de crédito e capital humano induziram positivamente o crescimento. Pires (2005), por outro lado, busca integrar a abordagem de King e Levine (1993b), que resgata o papel do sistema financeiro no crescimento econômico por meio de evidências empíricas com a análise de Stiglitz e Weiss (1981), que mostra o papel dos bancos no crescimento com base na teoria do racionamento de crédito. Sendo assim, o autor apresenta evidências para o caso dos municípios brasileiros no período entre 1991 e 2000, e os resultados mostram que o crédito é importante para explicar o seu crescimento.

Por fim, dentro da literatura que destaca o papel dos sistemas financeiros regionais destaca-se para o caso brasileiro, entre outros o trabalho de Crocco, Figueiredo e Santos (2010). ${ }^{10} \mathrm{O}$ objetivo é mostrar se existem estratégias bancárias diferenciadas na economia brasileira analisando, a partir da construção de indicadores, o balanço consolidado das agências bancárias das grandes regiões. As evidências encontradas sugerem que o sistema bancário atua de forma heterogênea no espaço, o que pode reforçar as desigualdades de desenvolvimento regionais existentes.

\subsection{Causalidade}

Os trabalhos empíricos que buscam determinar a relação de causalidade entre desenvolvimento do sistema financeiro e crescimento são vastos na literatura. Para o Brasil, a evidência parece suportar, de forma semelhante, a importância até aqui sugerida do sistema financeiro para a determinação do crescimento eco-

10 Ver também Almeida e Jayme Jr. (2008), Crocco, Santos e Amaral (2010b) e Cavalcante (2011). 
nômico. Nessa direção, destacam-se os trabalhos de Matos (2002), Marques Jr. e Porto Jr. (2004), Rocha e Nakane (2007), Zara (2006), entre outros, que tratam especificamente da relação de causalidade associados a esse problema.

Matos (2002) utiliza um conjunto de cinco variáveis para mensurar o desenvolvimento financeiro, quais sejam, a diferença nos agregados monetários M2 e o papel moeda em poder do público em relação a M2 e ao PIB, a razão entre o crédito bancário direcionado ao setor privado e o PIB, a divisão entre o crédito total do sistema financeiro direcionado ao setor privado pelo PIB e, por último, a proporção de M2 no PIB. O autor realiza testes de causalidade considerando um conjunto de séries temporais anuais entre 1947 e 2000, ou com séries menores, como no caso da razão crédito bancário ao setor privado/PIB, que se restringe ao período 1963-2000, enquanto a razão crédito do sistema financeiro ao setor privado/PIB cobre apenas o período 1970-2000. Os resultados obtidos revelam, em geral, evidências de relação causal positiva, unidirecional e significativa, entre desenvolvimento financeiro e crescimento econômico.

Marques Jr. e Porto Jr. (2004) avaliam a relação de causalidade entre desenvolvimento financeiro e crescimento econômico para o Brasil no período de 1950 a 2000. Para isso, os autores construíram três proxies para o desenvolvimento do sistema bancário e para o mercado de capitais brasileiro. Os resultados demonstram que a relação de causalidade é coerente com a literatura quando são considerados indicadores de desenvolvimento do sistema bancário. Todavia, quando a relação de causalidade é aplicada aos indicadores de desenvolvimento do mercado de capitais, a conclusão é contraditória.

A direção da causalidade usando uma metodologia diferente dos trabalhos anteriores é testada em Rocha e Nakane (2007). Nesse trabalho, utiliza-se o conceito de causalidade de Granger em um contexto de dados em painel e a análise é feita com uma amostra com dados anuais, compreendendo um painel com todos os estados brasileiros entre 1995 e 2002. Os principais resultados ressaltam que os componentes exógenos dos indicadores financeiros são estatisticamente significantes para a determinação do produto no Brasil. Sendo assim, parece haver evidência de que os indicadores financeiros utilizados causam o produto no sentido de Granger. Por outro lado, existe alguma evidência de causalidade em sentido contrário, ou seja, o produto causa o sistema financeiro no sentido de Granger quando é utilizada uma base de dados mensal. Segundo os autores, a inversão de resultados pode ser explicada pela natureza de longo prazo dos fenômenos por trás da relação entre sistema financeiro e produto, sendo que, no curto prazo, o sistema financeiro acaba por se tornar um mero reflexo das condições reais da economia.

Por fim, Zara (2006) utiliza um painel contendo as 27 unidades federativas do Brasil entre 1995 e 2003. Como proxy para os sistemas financeiros estaduais, utiliza- 
-se a razão entre o volume total de crédito bancário e o PIB de cada localidade. Os resultados obtidos pela autora, no entanto, não se mostram em consonância com a literatura empírica e teórica revisada há pouco, uma vez que o crédito estadual não apresenta qualquer significância estatística para a determinação do crescimento econômico local.

Como observado ao longo desta seção, os estudos empíricos para o Brasil apontam para o desenvolvimento do sistema financeiro como um importante componente capaz de determinar o crescimento econômico. Ademais, a maioria dos estudos demonstra que desenvolvimento financeiro causa o crescimento econômico. No entanto, ainda existe uma carência de estudos que possam suprir com análises mais específicas essa relação, sobretudo no que tange à possibilidade de uma influência desigual do desenvolvimento financeiro em uma perspectiva regional. Nesse sentido, a análise econométrica desenvolvida a seguir busca amenizar essa lacuna e contribuir para um melhor entendimento dessa relação a partir de um estudo que leva em consideração características regionais e de desenvolvimento das unidades federativas do Brasil. Ressalta-se, nesse caso, a pressuposição teórica de que existe uma relação positiva e unidirecional do desenvolvimento financeiro para com o crescimento econômico (essa pressuposição está ancorada em parte da abordagem tradicional e na abordagem keynesiana) e de que a relação de causalidade é aquela apontada pela literatura empírica (ou seja, que o desenvolvimento financeiro causa o crescimento econômico). Ademais, a realização do teste de causalidade em regressões quantílicas é problemático, porque as distribuições mudam ao longo do tempo, tanto na variável dependente (para a qual estamos tratando de explicar a distribuição), quanto nas dependentes (nesse caso, a composição de cada quantil ao longo do tempo).

\section{Material e Método}

Para o propósito deste trabalho, utiliza-se a técnica de regressão quantílica para dados empilhados ao longo do tempo, a qual permite analisar a associação existente entre a variável resposta (PIB das unidades federativas) com as variáveis explicativas (medidas de desenvolvimento financeiro) nos diversos quantis da distribuição condicional, possibilitando um mapeamento mais completo do impacto do desenvolvimento financeiro sobre o crescimento econômico. Isso é importante, pois permite detectar, em primeiro lugar, se ocorrem mudanças de sinal entre os quantis, ou seja, se o desenvolvimento financeiro tem influência distinta sobre o crescimento quando considerados os diferentes níveis de renda (quantis), e, em segundo lugar, se a magnitude desse impacto é diferente, o que pode determinar, por exemplo, uma influência crescente (decrescente) do desenvolvimento financeiro sobre o crescimento entre os quantis estimados. 
Ressalta-se que a regressão quantílica é uma técnica estatística baseada em uma generalização do conceito de regressão por mínimos quadrados ordinários (MQO), recorrendo à estimação de vários quantis da distribuição condicional associada ao modelo (KOENKER; HALLOCK, 2001). Enquanto os métodos de estimação usuais em modelos de regressão estimam o valor médio da distribuição condicional da variável dependente, a regressão quantílica permite a estimação de toda uma família de quantis, fornecendo informações mais específicas sobre a relação existente entre a variável resposta e as variáveis explicativas do modelo. A motivação inicial dessa técnica advém dos trabalhos pioneiros de Koenker e Bassett $(1978,1982)$.

As regressões quantílicas lidam melhor com o problema da heterocedasticidade, embora, ao calcular regressões para diferentes percentis, seja possível explorar a forma da distribuição condicional, o que é interessante, mesmo quando a heterocedasticidade não é a causa imediata de preocupação. Algumas vantagens inerentes à regressão quantílica sobre os MQO podem ser listadas da seguinte forma (KOENKER; BASSETT, 1978):

a) modelos podem ser usados para caracterizar a completa distribuição condicional da variável dependente, dado um conjunto de regressores;

b) a regressão quantílica tem uma representação de programação linear que facilita a estimação;

c) a função da regressão quantílica é uma soma ponderada dos desvios absolutos, o que dá uma medida robusta de alocação de modo que o vetor de coeficientes estimados não seja sensível aos outliers da variável dependente;

d) quando o erro não é normal, estimadores da regressão quantílica podem ser mais eficientes do que estimadores MQO; e

e) soluções diferentes em distintos percentis podem ser interpretadas como diferenças na resposta da variável dependente a mudanças nos regressores em vários pontos na distribuição condicional da variável dependente.

Formalmente, a regressão quantílica pode ser vista como uma extensão natural dos quantis amostrais para o caso de um modelo linear que assume a seguinte forma:

a) Como no cálculo da própria mediana, a regressão mediana pode ser definida pela minimização da soma absoluta dos erros - estimador Least absolute deviations (LAD) (e não, como nos $\mathrm{MQO}$, pela minimização da soma de seus quadrados); assim, os coeficientes da regressão mediana podem ser obtidos minimizando $\phi$, dado por $\phi=\sum_{i=1}^{n}\left|y_{i}-x_{i}^{\prime} \beta\right|=\sum_{i=1}^{n}\left(y_{i}-x_{i}^{\prime} \beta\right) \operatorname{sgn}\left(y_{i}-x_{i}^{\prime} \beta\right), \mathrm{em}$ que $\operatorname{sgn}(a)$ é o sinal de $a$, sendo 1 se $a>0$ e -1 se $a<0$ ou 0 , em que $y_{i}$ é vetor $m \times 1$ de variáveis endógenas, $x_{i}$ é vetor $m \times 1$ de variáveis exógenas e $\beta$ é uma matriz $m \times m$ de parâmetros. 
b) Regressões quantilicas, que não a mediana, são definidas pela minimização de:

$$
\phi_{q}=-(1-q) \sum_{y \leq x}\left(y_{i}-x_{i}^{\prime} \beta\right)+q \sum_{y>x, \beta}\left(y_{i}-x_{i}^{\prime} \beta\right)=\sum_{i=1}^{n}\left[q-1\left(y_{i} \leq x_{i}^{\prime} \beta\right)\right]\left(y_{i}-x_{i}^{\prime} \beta\right)
$$

em que $0<q<1$ é o quantil de interesse, e o valor da função $l(z)$ sinaliza a verdade (1), ou caso contrário (0) da proposição $z$. A condição de minimização é:

$$
\sum_{i} x_{i j}\left[q-1\left(y_{i} \leq x_{i}^{\prime} \beta\right)\right]=0 .
$$

A forma geral da equação a ser estimada é dada a seguir, representando o modelo de crescimento para dados em painel:

$$
g_{y i t}=\beta_{0}(\theta)+\beta_{1}(\theta) \log (D F)+\beta_{2}(\theta) Z_{i t}+\alpha_{i \theta}+\mu_{t \theta}+e_{i(\theta) t(\theta)}
$$

A variável dependente $\left(g_{\text {yit }}\right)$ é o PIB (nominal) da unidade federativa i no período $t$ analisado; $D F$ é a variável que representa o desenvolvimento do sistema financeiro; $Z$ são as variáveis de controle; $\beta_{1}$ e $\beta_{2}$ são os parâmetros a serem estimados; $\alpha_{i \theta}$ é o efeito fixo de cada região; e $\mu_{t \theta}$ é o efeito especifico de tempo. ${ }^{11}$ Deve-se ressaltar que um dos objetivos é verificar se o desenvolvimento financeiro aumenta o nível de renda das unidades federativas brasileiras. Em termos teóricos, o ponto de partida é a literatura revista há pouco, uma vez que todas as conclusões obtidas para o crescimento econômico necessariamente têm implicações equivalentes sobre o nível de renda da economia.

Para testar o modelo, será adotada, em primeiro lugar, uma estratégia inspirada no trabalho de King e Levine (1993b). Nesse caso, a análise empírica irá explorar o impacto de duas variáveis financeiras (como proxy para desenvolvimento do sistema financeiro) sobre o crescimento econômico, sendo estas: a) depósitos à vista (depvista); e b) depósitos a prazo (deprazo). A segunda estratégia baseia-se no desenvolvimento de alguns indicadores para o grau de desenvolvimento do sistema financeiro (DF). ${ }^{12}$ Nesse caso, quantificou-se o desenvolvimento do siste-

11 Para captar o efeito fixo e o efeito específico de tempo utilizaram-se variáveis dummies que, para fins de simplificação, não serão reportadas.

12 Esses indicadores foram adaptados de Marques Jr. e Porto Jr. (2004). Segundo os autores, mensurar o conceito de desenvolvimento financeiro é um problema corrente na literatura. Por isso, optou-se por seguir essa estratégia baseada nessas três dimensões, o que capta mais fielmente esse conceito. Não obstante, alguns dados utilizados pelos autores, especialmente "crédito ao setor privado", não se encontram disponíveis para as unidades federativas. Nesse caso, o indicador do nível de atividade no mercado é diferente do proposto pelos autores. Observa-se, ainda, que a utilização de variáveis como "créditos" e "débitos" buscam captar diferentes "funções" do desenvolvimento financeiro que afetam o crescimento. No primeiro caso, tenta-se captar a contribuição do sistema bancário à capacidade de investimento de um país e, por conseguinte, ao crescimento econômico, ao passo que no segundo caso assume-se a perspectiva de um sistema 
ma financeiro ao longo do tempo em três dimensões: o tamanho do setor, o nível de atividade e a eficiência do sistema financeiro. A ideia subjacente é a de que, quanto maior o volume de empréstimos, maior a atividade do sistema bancário, e quanto mais se transformar depósito em crédito, mais eficiente é esse sistema. Especificamente, os indicadores utilizados foram: a) passivo exigível (soma dos depósitos à vista e a prazo) sobre PIB (TamSB) como proxy para o tamanho do mercado; b) crédito do sistema financeiro sobre o PIB (NivSB1) e empréstimos sobre o PIB (NivSB2) como proxy para o nível de atividade no mercado; ${ }^{13}$ e c) e o resultado da divisão do valor do crédito total pelos depósitos totais dividido pelo PIB (EficSB) para captar a eficiência do mercado.

Além disso, realizou-se o exercício econométrico que busca captar o argumento pós-keynesiano (ver seção 2). Nesse caso, as variáveis utilizadas foram: d) PLB, que é construída dividindo-se o total de depósitos à vista pelo total das operações de crédito, e PLP, que é dada pela razão entre os depósitos à vista e os depósitos totais.

O índice de PLB foi criado por Crocco, Cavalcante e Castro (2005). ${ }^{14}$ Ele capta a magnitude em que o banco opta por disponibilizar seus ativos de maior prazo em relação a suas obrigações mais imediatas. As contas utilizadas refletem, respectivamente, a disposição do público em manter seus ativos o mais líquido possível (depósitos à vista) e a intenção dos bancos em emprestar, ou seja, diminuir a liquidez de seus ativos (crédito total). Assim, um aumento na PLB afetará negativamente a sua disposição em realizar operações de crédito (o que reduz o denominador e, consequentemente, aumenta o índice PLB). Essa disposição em realizar operações de crédito pode variar de uma região para outra, levando, no longo prazo, a um diferente multiplicador bancário (entre as regiões) e, consequentemente, a uma distinta influência do sistema financeiro sobre o crescimento regional. Em outras palavras, ainda que se tenha um sistema bancário com abrangência nacional e gestão centralizada, é possível que ele atue de forma diferenciada em cada região. A justificativa para essa diferenciação na preferência pela liquidez advém das incertezas geográficas associadas ao dinamismo e à possibilidade de instabilidade e incertezas percebidas pelos bancos em cada região. Ademais, é justamente essa forma diferenciada de atuação dos bancos, decorrentes de características geográficas regionais, que podem explicar a existência de regiões captadoras e apli-

bancário mobilizador de recursos que, ao captar depósitos, convertendo-os em empréstimos, beneficia o crescimento. Por um lado, porque permite às firmas um horizonte de investimento mais longo e, por outro, porque garante certa liquidez aos depositantes.

13 Empréstimo remete às contas como credito de curto prazo, capital de giro, empréstimo ao consumidor, desconto de duplicata, entre outras, enquanto crédito é a soma de todas elas.

14 Entre outros trabalhos que utilizam esse índice, ver Cavalcante, Crocco e Jayme Jr. (2006) e Nogueira, Figueiredo e Crocco (2008). 
cadoras de recursos, o que suporta a possibilidade de uma relação desigual entre desenvolvimento financeiro e crescimento econômico do ponto de vista regional.

Evidentemente, esse índice tem suas limitações. Em primeiro lugar, deve-se ressaltar que o conceito de preferência pela liquidez (que difere, dinamicamente, segundo o tipo de portfólio do tipo de agente em questão) envolve a expectativa dos agentes (e sua dinâmica) e, portanto, é um conceito de difícil quantificação. Nesse sentido, o índice foi construído para captar decisões de administração do portfólio dos bancos, que logicamente envolve a gestão de ativos e passivos já que o banco administra sua liquidez conforme a liquidez do finance (crédito) e do funding (depósitos). Outros índices, com limitações semelhantes, poderiam ser indicados para captar essa PLB, como, por exemplo, a relação entre crédito total sobre depósitos total e/ou ativo circulante sobre ativo realizável (ou total). Não obstante, além da questão das expectativas, esses índices se aproximam mais de indicadores de desenvolvimento financeiro além de envolverem (sobretudo o segundo) diferentes ativos (caixa, títulos, crédito) que possuem diferentes características de liquidez.

Nesse contexto, considerando a disponibilidade de opções e suas limitações, optou-se pela referida aferição do conceito de preferência pela liquidez considerando ainda que, do ponto de vista da literatura pós-keynesiana, é plausível, ${ }^{15}$ como proxy, relacionar o passivo mais líquido no balanço dos bancos (depósitos, base do funding) com seu ativo de menor liquidez (considerando que títulos têm liquidez maior) para entender como o banco decide, segundo essas informações, administrar seu portfólio (emprestar menos ou mais). Entende-se, assim, que esse indicador melhor se aproxima da ideia de PLB, incorporando decisões que vão além daquela relacionada à alocação de ativos.

Por outro lado, quanto maior a PLP, maiores as posições em ativos líquidos desses agentes e menores as suas demanda por crédito. Isso significa que a preferência por depósitos à vista será maior e, consequentemente, maior será o índice PLP. Todavia, esse índice possui duas limitações: a) os depósitos a prazo e de poupança têm liquidez imediata, inclusive permitindo transferências automáticas, o que os torna substitutos muito próximos de depósitos à vista; e b) durante todo o período analisado, os fundos de investimento são uma parcela relevante dos ativos financeiros no Brasil, também com liquidez imediata e transformação automática em depósitos à vista. O estoque de aplicações em fundos de investimento em relação aos depósitos totais no sistema financeiro vai de 14\% a 107\% entre 1995 e 2004. Como o volume de recursos em fundos é muito alto em comparação com

15 Em especial, considerando os estágios finais de desenvolvimento do sistema financeiro, conforme Chick (1992), e a ideia de administração de portfólios e suavidade do circuito finance-funding, de Studart (1995). 
os de depósitos, mas os dados de fundos por unidade federativa não existem, é possível que o índice PLP sofra algum tipo de limitação.

O resultado esperado das estimações é de que, quanto maior o desenvolvimento do sistema financeiro (representado pelas variáveis financeiras e pelos indicadores construídos) maior deve ser o nível de renda das unidades federativas. Ou seja, espera-se uma relação positiva entre essas duas variáveis. Uma exceção é feita em relação aos resultados do último exercício econométrico, uma vez que, quanto maior a PLB e a PLP, menor tende ser a oferta de crédito e, assim, o nível de renda.

Foram estabelecidos alguns controles utilizados usualmente na literatura, que envolvem: a renda do período inicial (renda) para mensurar o efeito da convergência; o número de anos de estudo da população acima de 25 anos como medida para capital humano (educ); o grau de abertura de cada unidade federativa calculado como a soma das exportações mais importações sobre o PIB (open); uma variável que representa os gastos do governo como proporção do PIB em educação e cultura (educul), outra em saúde e saneamento (sausan) ${ }^{16}$ e outra na esfera jurídica (júri); e uma variável que faz controle para o progresso tecnológico. Esta é construída como proxy a partir da soma de dois indicadores: o número de patentes e desenhos industriais registrados no Instituto Nacional da Propriedade Industrial (Inpi) e o número de artigos científicos registrados no Institute for Scientific Information (ISI). Infelizmente, esses dados estão disponíveis somente para o período entre 1997 e 2004. Assim, as regressões que incorporam essa variável são estimadas apenas com base nessa subamostra de períodos. Além disso, todas as variáveis foram transformadas pelo logaritmo em sua base natural.

A escolha desse conjunto de variáveis de controle se justifica por serem correspondentes, ou proxy, para as variáveis que são amplamente utilizadas em trabalhos empíricos. Evidentemente, existem algumas limitações. Em primeiro lugar, no que se refere à variável open devemos considerar que, como o presente estudo é aplicado às unidades da federação, o ideal seria considerar também importações e exportações provenientes de outros estados. No entanto, a base de dados não está disponível. Foram utilizados, assim, dados de transações comerciais com outros países, o que, por sua vez, requer a ressalva de que possíveis distorções podem ser geradas pelo fato de as exportações e importações serem contabilizadas de acordo com a localização jurídica do importador ou exportador e não necessariamente com a origem produtiva ou destinação final do produto. Em segundo, no que se refere à proxy para educação, devemos considerar que, em geral, como as formas e regras de funcionamento do sistema de ensino são as mesmas entre as unidades

16 Essa variável busca captar se uma melhor "saúde" dos trabalhadores tem efeitos positivos sobre o crescimento, como sugere a evidência empírica recente. Ver, entre outros, Barro (1996) e Bloom, Canning e Sevilla (2001). 
federativas, é possível que a qualidade da educação seja tão ou mais importante do que a quantidade de educação recebida. Essa é uma dimensão importante não captada pela variável proposta.

Uma limitação adicional reside no fato de que a série para os dados disponíveis é reduzida, além de ser construída a partir de fontes diferentes. Isso implica, por exemplo, que o reduzido período de análise pode não captar o efeito da convergência, uma vez que essa é uma hipótese de longo prazo. Contudo, a principal dificuldade do modelo a ser estimado é a possível presença da endogeneidade, que surge quando alguma variável omitida presente no termo de erro está correlacionada com alguma variável explicativa. Por exemplo, a endogeneidade pode estar presente caso as variáveis que representam instituições não sejam consideradas explicitamente.

Existe certo consenso na literatura que "boas" instituições são favoráveis ao crescimento (ACEMOGLU, 2009). Todavia, essa literatura enfrenta no mínimo dois problemas: o primeiro, de ordem empírica, refere-se à definição de instrumentos e/ou proxies apropriadas para a qualidade das instituições; o segundo, do ponto de vista teórico, relaciona-se ao desafio de explicar as diferenças de crescimento de um determinado país ou região sujeito ao mesmo marco regulatório. ${ }^{17}$

Mais especificamente, como seria possível explicar as disparidades entre as trajetórias de desenvolvimento no Brasil, uma vez que o arcabouço macroinstitucional é constante? Segundo Naritomi (2007), para entender os padrões observados dentro do país, é preciso investigá-las na esfera local a partir de dimensões mais concretas do que aquelas mais comumente discutidas na literatura. Ao mesmo tempo, devido à constância das macroinstituições no território e ao caráter fortemente centralizado da federação brasileira, é necessário avançar no entendimento das diferenças entre os papéis de instituições de facto e de jure, isto é, entre o funcionamento efetivo das instituições e o que está formalmente estabelecido. Em outros termos, aqui se argumenta que, apesar da existência de um corpo legal em sua maior parte comum entre as regiões brasileiras, as instituições informais variam entre as unidades federativas, ou seja, as instituições atuais são endógenas, pois derivam da própria trajetória de desenvolvimento das regiões. Além disso, deve-se ressaltar que a literatura para o caso brasileiro é ampla no sentido de mostrar que as variáveis relacionadas ao "desenvolvimento regional" são importantes para explicar o desenvolvimento e as disparidades existentes entre as distintas regiões do país (DINIZ, 1993; AZZONI, 1997, entre outros).

17 Deve-se ressaltar que o conceito de instituições é mais amplo do que o conceito de marco regulatório. Segundo Hodgson (2001, p. 295), "Essentially, institutions are durable systems of established and embedded social rules and conventions that structure social interactions". Para uma discussão detalhada ver, entre outros, Hodgson (2003, 2001) e Conceição (2000). 
Dado esse problema, a estratégia adotada neste trabalho consiste em, na impossibilidade de trabalhar com um indicador representativo da qualidade das instituições locais e do "desenvolvimento regional", estabelecer dummies regionais.

Os dados utilizados correspondem ao período de 1995 a 2004 e foram obtidos das seguintes fontes: a) variáveis financeiras: do Sistema de Informações da Banco Central do Brasil (Sisbacen); b) proxy para progresso tecnológico: do Inpi e do ISI; c) valor das exportações e importações: do Ministério do Desenvolvimento, Indústria e Comércio Exterior; e d) as demais variáveis: do Ipeadata.

\section{Resultados Empíricos}

Inicialmente, faz-se útil considerar alguma descrição dos dados relativos ao sistema bancário brasileiro. ${ }^{18} \mathrm{~A}$ participação e a evolução ao longo do período de alguns atributos bancários, como o volume total de crédito e o volume total de empréstimos, demonstram que a região sudeste se destaca em todos esses atributos, evidenciando a presença de desequilíbrios regionais no Brasil (ver Gráficos 1 e 2).

Gráfico 1 - Evolução do crédito total, por regiões

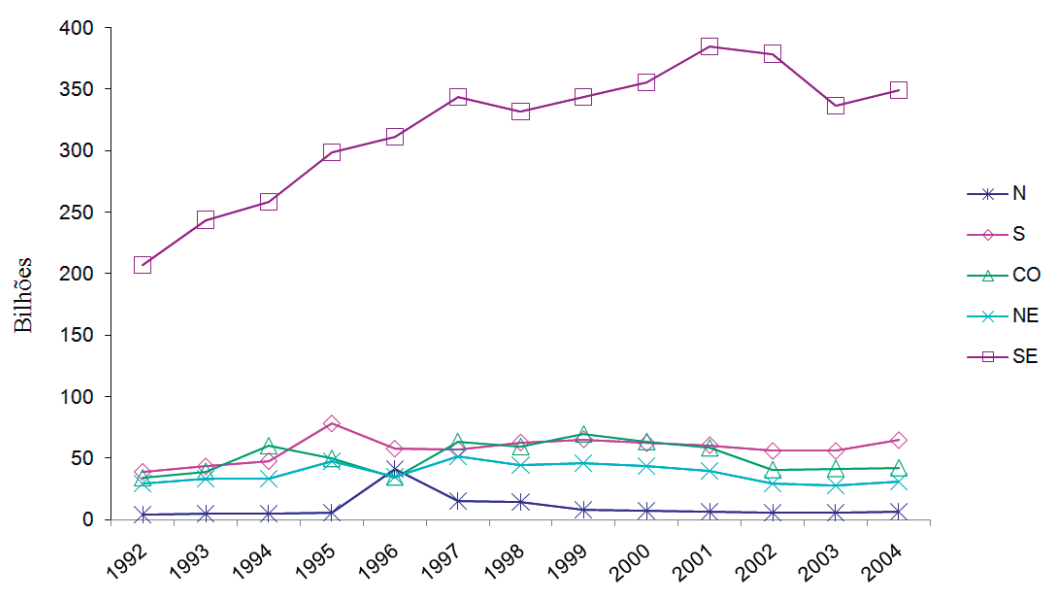

Fonte: Elaboração própria.

18 Os exercícios econométricos foram realizados com o auxílio do programa Stata. 
Gráfico 2 - Total de empréstimo, por regiões

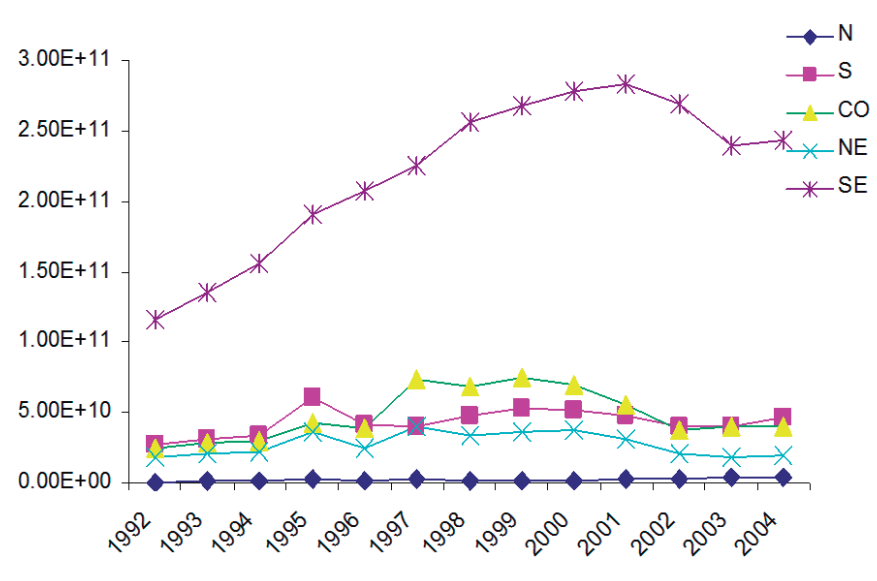

Fonte: Elaboração própria.

O Quadro 1 apresenta os índices de PLB e de PLP para o ano de 1995. Em princípio, pode-se observar que esses índices são coerentes com a teoria, uma vez que são maiores para as unidades federativas menos desenvolvidas, captando o argumento teórico de que as regiões mais remotas, por apresentarem maior grau de incerteza, tendem a manter seus ativos mais líquidos. O maior grau de incerteza em regiões menos desenvolvidsas está associado ao baixo dinamismo e à sua instabilidade econômica, levando os agentes a preferirem reter uma maior parcela de ativos líquidos (entre eles moeda) na composição de seus portfólios. Isso significa, por um lado, uma maior PLP, ou seja, uma maior participação dos depósitos à vista sobre os depósitos totais (já que os depósitos a vista podem ser transformados em moeda rapidamente) e, por outro, uma maior PLB. Essa maior PLB pode ser explicada pelo baixo dinamismo e pela instabilidade econômica característica dessas regiões (o que, por exemplo, aumenta o risco de default dos empréstimos) e, adicionalmente, pela falta de informações confiáveis referentes aos projetos das regiões remotas, ou mesmo, pela maior distância entre o emprestador (banco) e o tomador de recursos. ${ }^{19}$

19 Uma explicação alternativa está relacionada à diferença de custos de transação e escala de operações no sistema financeiro, originadas em diferenças regionais de atividades econômicas, demográficas e de renda. 
Quadro 1 - Valor do índice da PLB e da PLP, por unidade federativa, para o ano de 1995

\begin{tabular}{|c|c|c|c|c|c|c|c|c|c|c|c|c|c|c|}
\hline UF & AC & AL & AM & AP & BA & CE & DF & ES & GO & MA & MG & MS & MT & PA \\
\hline PLP & 0,62 & 0,34 & 0,35 & 0,67 & 0,19 & 0,15 & 0,05 & 0,2 & 0,49 & 0,51 & 0,15 & 0,57 & 0,62 & 0,27 \\
\hline PLB & 0,38 & 0,9 & 0,21 & 0,84 & 0,06 & 0,07 & 0,08 & 0,13 & 0,06 & 0,14 & 0,08 & 0,05 & 0,06 & 0,15 \\
\hline Rank & $4^{\circ}$ & $3^{\circ}$ & $11^{\circ}$ & $1^{\circ}$ & $18^{\circ}$ & $20^{\circ}$ & $25^{\circ}$ & $17^{\circ}$ & $12^{\circ}$ & $9^{\circ}$ & $19^{\circ}$ & $10^{\circ}$ & $8^{\circ}$ & $15^{\circ}$ \\
\hline UF & PB & PE & PI & PR & RJ & RN & RO & RR & RS & SC & SE & SP & TO & \\
\hline PLP & 0,61 & 0,18 & 0,58 & 0,13 & 0,14 & 0,4 & 0,65 & 0,79 & 0,14 & 0,29 & 0,38 & 0,09 & 0,39 & \\
\hline PLB & 0,16 & 0,05 & 0,16 & 0,03 & 0,07 & 0,14 & 0,28 & 0,47 & 0,06 & 0,11 & 0,18 & 0,05 & 0,12 & \\
\hline Rank & $6^{\circ}$ & $19^{\circ}$ & $7^{\circ}$ & $23^{\circ}$ & $21^{\circ}$ & $13^{\circ}$ & $5^{\circ}$ & $2^{\circ}$ & $22^{\circ}$ & $16^{\circ}$ & $11^{\circ}$ & $24^{\circ}$ & $14^{\circ}$ & \\
\hline
\end{tabular}

Fonte: Elaboração própria.

Nota: "O rank foi construído a partir da média aritmética dos dois índices. A unidade federativa com maior média recebeu o rank $1^{\circ} \mathrm{e}$, assim, sucessivamente.

A seguir são apresentados os resultados do exercício econométrico. A Tabela 1 apresenta as estimativas pelo método $\mathrm{MQO}$. Os resultados encontrados para as variáveis que captam o desenvolvimento do sistema financeiro estão, em grande parte, de acordo com o esperado. Mais especificamente, observa-se que os resultados são positivos e significativos no sentido de que um maior desenvolvimento do sistema financeiro (depvista e deprazo) impacta positivamente sobre o nível de renda. Estimou-se, ademais, o efeito do crédito sobre a variável dependente, e o resultado encontrado foi o esperado, uma vez que o coeficiente apresentou sinal positivo e significativo a $1 \%$. Por outro lado, os resultados encontrados para as estimativas envolvendo os indicadores de desenvolvimento do sistema financeiro são contraditórios. O indicador de tamanho do mercado (tamSB) foi significativo a $1 \%$ e apresentou o sinal esperado (positivo), ao passo que o indicador de eficiência (eficsb) apresentou sinal contrário ao esperado (negativo e significante a 5\%). Os outros dois indicadores foram não significativos. Por fim, os indicadores que representam a PLP e a PLB apresentaram o sinal esperado (negativo), corroborando o argumento pós-keynesiano de que quanto maior a preferência pela liquidez, menor tende a ser a oferta de crédito e, assim, menor será o crescimento. 
Tabela 1 - Resultados das regressões por MQO para os diversos indicadores de desenvolvimento do sistema financeiro (1995-2004)

\begin{tabular}{|c|c|c|c|c|c|c|c|c|c|}
\hline $\begin{array}{l}\text { Variável } \\
\text { dependente: } \\
\text { PIB } \\
\text { estadual }\end{array}$ & I & II & III & IV & $\mathbf{V}$ & VI & VII & VIII & IX \\
\hline Constante. & $-0,763 * *$ & $1,394^{*}$ & $0,652 * *$ & $1,090^{*}$ & $1,055^{*}$ & $1,20^{*}$ & $1,26^{*}$ & $1,313^{*}$ & $1,749^{*}$ \\
\hline Renda & $0,770^{*}$ & $0,835^{*}$ & $0,840^{*}$ & $0,955^{*}$ & $0,964^{*}$ & $0,971^{*}$ & $0,849^{*}$ & $0,953^{*}$ & $0,925^{*}$ \\
\hline Educ & $\begin{array}{l}- \\
0,098^{* * *}\end{array}$ & $-0,086$ & $-0,050$ & $-\overline{1} 18^{* * *}$ & - $0,109^{* * *}$ & $-0,130 * *$ & $-0,158 *$ & $-0,092$ & $\begin{array}{l} \\
0,109^{* * *}\end{array}$ \\
\hline Open & $-0,0239 *$ & $-0,0079$ & $\overline{0}, 014^{* * *}$ & $-\overline{0} 016^{* * *}$ & $0,018^{* * *}$ & $-\overline{0} 018^{* * *}$ & $-0,0145$ & $-0,0150$ & $-0,010$ \\
\hline Educul & $-0,008$ & $-0,0088$ & $-0,005$ & $-0,003$ & 0,0005 & 0,0030 & $-0,003$ & 0,001 & $-0,005$ \\
\hline Sausan & $-0,0519 *$ & $-0,065^{*}$ & $-0,033 * *$ & $-0,044^{*}$ & $0,026^{* * * *}$ & $-0,0219$ & $-0,052 *$ & $-0,020$ & $-0,053 *$ \\
\hline Júri & 0,014 & $0,0197 * * *$ & 0,009 & 0,016 & 0,0126 & 0,0143 & $0,021^{* *}$ & 0,0109 & $0,018^{* * *}$ \\
\hline Depvista & $0,229 *$ & - & - & - & - & - & - & & \\
\hline Deprazo & - & 0,089 * & - & - & - & - & - & & \\
\hline Credit & - & - & 0,111* & & & & & & \\
\hline TamSB & - & - & - & $0,0527^{*}$ & - & - & - & & \\
\hline NivSB1 & - & - & - & - & 0,028 & - & - & & \\
\hline NivSB2 & - & - & - & - & - & $-0,0133$ & - & & \\
\hline EficSB & - & - & - & - & - & - & $-0,114^{*}$ & & \\
\hline PLB & - & - & - & - & - & - & - & $\begin{array}{c}- \\
0,058^{* *}\end{array}$ & \\
\hline PLP & - & - & - & - & - & - & - & & $-0,1207^{*}$ \\
\hline$R^{2}$ & 0,992 & 0,992 & 0,99 & 0,99 & 0,990 & 0,99 & 0,99 & 0,9846 & 0,99 \\
\hline
\end{tabular}

Fonte: Elaboração própria.

Nota: * significante ao nível de 1\%; ** significante ao nível de 5\%; *** significante ao nível de $10 \%$.

O sinal do coeficiente associado à renda inicial do período foi positivo e estatisticamente significativo a 1\%, confirmando que a hipótese de convergência da renda não pode ser sustentada a partir das evidências encontradas. Dentre as variáveis de controle, destacam-se os resultados para os coeficientes associados à educação e à abertura comercial, por apresentarem sinal contrário ao apontado pela literatura (ver seção 4). Para a abertura comercial, uma justificativa plausível para o sinal encontrado refere-se ao fato de que o período de análise corresponde a um período em que houve uma série de crises internacionais, associado a períodos de grande valorização e desvalorização da moeda nacional, o que trouxe uma série de dificuldades do ponto de vista do comércio internacional.

As estimativas da regressão quantílica revelam, pela Tabela 2, que a variável explicativa (depvista) tem o sinal esperado e é significativa a $5 \%$ em todos os quantis estimados, revelando que o desenvolvimento do sistema financeiro afeta positivamente o nível de renda das unidades federativas brasileiras. Destaca-se, nesse caso, que a magnitude do parâmetro aumenta à medida que se aproximam dos quantis superiores da distribuição. As variáveis de controle, em sua grande maioria, mostram ser não significativas, com exceção feita àquela que representa os gastos em saúde e saneamento como proporção do PIB, que apresentou sinal negativo e estatisticamente significativo em quatro dos cinco quantis estimados. 
No segundo caso, a variável deprazo é significante a $1 \%$ em todos os quantis estimados e a magnitude do parâmetro diminui do primeiro para o quarto quantil (de 0,074 para 0,064 , respectivamente), voltando a crescer no último quantil analisado $(0,070)$, mostrando novamente que o desenvolvimento do sistema financeiro têm efeitos positivos sobre o nível de renda.

Tabela 2 - Resultado das regressões quantílicas para depósitos à vista e depósitos a prazo como indicadores de desenvolvimento do sistema financeiro (1995-2004)

\begin{tabular}{|c|c|c|c|c|c|c|c|c|c|c|c|}
\hline \multirow{2}{*}{$\begin{array}{l}\text { Variável } \\
\text { dependente: } \\
\text { PIB } \\
\text { estadual } \\
\end{array}$} & \multicolumn{5}{|c|}{ Quantil } & \multicolumn{6}{|c|}{ Quantil } \\
\hline & 0,1 & 0,25 & 0,5 & 0,75 & 0,9 & & 0,1 & 0,25 & 0,5 & 0,75 & 0,9 \\
\hline Const.ante & $-0,271$ & - $0,704^{* *}$ & - $0,96^{* * * *}$ & $-0,285$ & $-0,083$ & Constante & 0,321 & 0,49 & $0,81^{* *}$ & $1,26^{*}$ & $1,76^{*}$ \\
\hline Renda & $0,911^{*}$ & $0,832^{*}$ & $0,804^{*}$ & $0,769^{*}$ & $0,702^{*}$ & Renda & $0,88^{*}$ & $0,885^{*}$ & $0,87^{*}$ & $0,84^{*}$ & $0,818^{*}$ \\
\hline Educ & $-0,133$ & $0,020^{* * *}$ & $-0,047$ & $-0,012$ & $-0,015$ & educ & $-0,126$ & $-0,122$ & - $0,08^{* * * *}$ & $-0,012$ & 0,035 \\
\hline Open & $-0,023$ & $-0,030^{*}$ & $-0,038^{*}$ & $-0,011$ & $-0,006$ & open & $-0,017$ & $-0,018$ & $-0,012$ & 0,007 & 0,011 \\
\hline Educul & $-0,010$ & $-0,006$ & $-0,004$ & $-0,002$ & 0,002 & educul & $-0,009$ & $-0,003$ & $-0,002$ & $-0,004$ & 0,006 \\
\hline Sausan & - $0,04 * * *$ & $-0,045^{*}$ & - $0,034^{* *}$ & $\begin{array}{l}- \\
0,029 *\end{array}$ & $-0,023$ & sausan & - $0,05^{* * *}$ & - $0,063^{* *}$ & $-0,04^{*}$ & $-0,06^{*}$ & $-0,023$ \\
\hline Júri & 0,023 & $0,020^{*}$ & 0,0109 & $\begin{array}{l}- \\
0,0005\end{array}$ & $\begin{array}{l}- \\
0,0005\end{array}$ & Júri & 0,031 & $0,036^{* * *}$ & 0,011 & $0,020^{*}$ & $0,016^{* *}$ \\
\hline Depvista & 0,090 *** & $0,173 *$ & $0,206^{*}$ & $0,208^{*}$ & $0,260 *$ & deprazo & $0,074^{*}$ & $0,069 *$ & $0,068^{*}$ & $0,064^{*}$ & $0,070 *$ \\
\hline Pseudo $R^{2}$ & 0,93 & 0,92 & 0,92 & 0,92 & 0,92 & $\begin{array}{l}\text { Pseudo } \\
R^{2}\end{array}$ & 0,93 & 0,92 & 0,91 & 0,91 & 0,91 \\
\hline
\end{tabular}

Fonte: Elaboração própria.

Nota: * significante ao nível de 1\%; * * significante ao nível de 5\%; *** significante ao nível de $10 \%$.

Os resultados para os indicadores de desenvolvimento do sistema financeiro propostos são reportados nas Tabelas 3, 4 e 5. No primeiro caso (ver Tabela 3), o coeficiente associado ao indicador tamanho de mercado mostrou-se significativo e com o sinal esperado somente no último quantil estimado (0.067). Deve-se ressaltar que esse indicador apresentou sinal negativo para o primeiro quantil (-0,009), o que, ainda que não significativo, pode sugerir uma relação inversa entre tamanho de mercado e nível de renda para as unidades federativas menos desenvolvidas. Essa relação negativa para o primeiro quantil é novamente encontrada no indicador nível de atividade (1) do sistema bancário, que apresentou coeficientes significativos para o primeiro e último quantil com sinal negativo e positivo, respectivamente. Uma possível explicação para a presença de uma relação inversa nos primeiros quantis, como observado anteriormente, advém do fato de que em regiões menos desenvolvidas, onde persiste um ambiente de incerteza crescente, os bancos podem oferecer menos crédito e menos empréstimos, dada a estrutura econômica dessas regiões e o remoto controle da sede bancária sobre suas filiais. Ainda, é possível que o sistema financeiro presente nessas regiões atue captando e transferindo recursos dessas para outras regiões mais desenvolvidas (menor grau de incerteza), aprofundando assim as desigualdades de renda existentes entre si. 
Tabela 3 - Resultados das regressões quantílicas para tamanho e nível de atividade (1) do sistema bancário como indicadores de desenvolvimento do sistema financeiro (1995-2004)

\begin{tabular}{|c|c|c|c|c|c|c|c|c|c|c|c|}
\hline \multirow{2}{*}{$\begin{array}{c}\text { Variável } \\
\text { dependente: } \\
\text { PIB } \\
\text { estadual } \\
\end{array}$} & \multicolumn{5}{|c|}{ Quantil } & \multicolumn{6}{|c|}{ Quantil } \\
\hline & 0,1 & 0,25 & 0,5 & 0,75 & 0,9 & & 0,1 & 0,25 & 0,5 & 0,75 & 0,9 \\
\hline Constante & 0,057 & 0,246 & $1,14^{*}$ & $1,64^{*}$ & $1,95^{*}$ & Constante & $-0,177$ & 0,133 & $0,840^{*}$ & $1,190 *$ & $1,10^{*}$ \\
\hline Renda & $1,02^{*}$ & $0,99^{*}$ & $0,961^{*}$ & $0,932^{*}$ & $0,905^{*}$ & Renda & $1,03^{*}$ & $1,00^{*}$ & $0,963^{*}$ & $0,937^{*}$ & $0,930^{*}$ \\
\hline Educ & $-0,09^{*}$ & $-0,073$ & $\stackrel{-}{-}$ & $-0,032$ & 0,038 & educ & $-0,138$ & $-0,073$ & $-0,127^{*}$ & $-0,043$ & $-0,010$ \\
\hline Open & $-0,038^{*}$ & $\overline{-}_{0,031^{* *}}$ & $-0,014$ & 0,0018 & 0,003 & open & $-0,037^{*}$ & $-0,029^{*}$ & $\overline{-}^{-}, 015^{\text {** }}$ & $\begin{array}{c}- \\
0,0004\end{array}$ & $-0,008$ \\
\hline Educul & $\begin{array}{c}- \\
0,007^{* * * *}\end{array}$ & 0,009 &, 0017 & 0,003 & 0,008 & educul & $-0,004$ & 0,002 & 0,003 & 0,004 & $0,011^{* *}$ \\
\hline Sausan & $-0,044^{*}$ & $\begin{array}{c}- \\
0,044^{* *}\end{array}$ & $-0,014$ & $\begin{array}{c}-\overline{-} \\
0,037^{*}\end{array}$ & $-0,016$ & sausan & $-0,040^{*}$ & $-0,037^{*}$ & $-0,008$ & $\begin{array}{c}-0,027 \\
* *\end{array}$ & $-0,004$ \\
\hline Júri & 0,043 & 0,019 & 0,0018 & $0,023^{*}$ & 0,011 & júri & $0,047^{*}$ & $0,0268^{*}$ & 0,0001 & 0,0178 & 0,010 \\
\hline TamSB & $-0,009$ & 0,030 & 0,017 & 0,026 & $0,067^{* * *}$ & NivSB1 & $\overline{-}$ & $-0,0158$ & 0,0138 & 0,0258 & $0,062^{* *}$ \\
\hline Pseudo $R^{2}$ & 0,93 & 0,92 & 0,91 & 0,91 & 0,91 & $\begin{array}{c}\text { Pseudo } \\
R^{2}\end{array}$ & 0,93 & 0,92 & 0,91 & 0,91 & 0,91 \\
\hline
\end{tabular}

Fonte: Elaboração própria.

Nota: * significante ao nível de 1\%; ** significante ao nível de 5\%; *** significante ao nível de $10 \%$.

A estimativa para o segundo indicador do nível de atividade (2) (ver Tabela 4) do sistema bancário exibe um comportamento semelhante ao indicador anterior. $\mathrm{O}$ coeficiente muda de sinal ao longo da distribuição, sendo negativo para os quantis inferiores e positivo para os superiores. Todavia, esse coeficiente é significativo somente para os quantis inferiores $(0,10$ e 0,25$)$. Entre as variáveis de controle, destaca-se a variável júri por apresentar coeficiente positivo para três dos cinco quantis estimados. Isso significa que investimentos garantidores do cumprimento da lei têm impactos positivos sobre o nível de renda, sobretudo nas unidades federativas menos desenvolvidas, onde o ambiente de incerteza é maior. O coeficiente associado ao indicador de eficiência do sistema bancário apresentou sinal contrário ao esperado e foi significativo ao longo de toda a distribuição ao nível de significância 1\%. A magnitude do parâmetro variou consideravelmente entre os quantis estimados, de um máximo de 0,094 no quantil inferior para um mínimo de 0,078 no quantil superior. 
Tabela 4 - Resultados das regressões quantílicas para nível de atividade (2) e eficiência do sistema bancário como indicadores de desenvolvimento do sistema financeiro (1995-2004)

\begin{tabular}{|c|c|c|c|c|c|c|c|c|c|c|c|}
\hline $\begin{array}{l}\text { Variável } \\
\text { dependente: } \\
\text { PIB }\end{array}$ & \multicolumn{5}{|c|}{ Quantil } & \multicolumn{6}{|c|}{ Quantil } \\
\hline & 0,1 & 0,25 & 0,5 & 0,75 & 0,9 & & 0,1 & 0,25 & 0,5 & 0,75 & 0,9 \\
\hline Constante & $-0,173$ & 0,232 & $0,971^{*}$ & $1,22 *$ & $1,03^{* *}$ & Constante & 0,387 & 0,412 & $0,63^{* * *}$ & $1,05^{*}$ & $1,68^{*}$ \\
\hline Renda & $1,02 *$ & $0,999 *$ & $0,962 *$ & $0,94 *$ & $0,945^{*}$ & Renda & $0,892^{*}$ & $0,909^{*}$ & $0,88^{*}$ & $0,86^{*}$ & $0,84^{*}$ \\
\hline Educ & $\begin{array}{l}- \\
0,116 * *\end{array}$ & $-0,102 *$ & $\begin{array}{l}- \\
0,11 * * *\end{array}$ & $-0,049$ & $-0,036$ & educ & $-0,20 *$ & $\begin{array}{l}- \\
0,155^{*}\end{array}$ & $\begin{array}{l}- \\
0,141 * *\end{array}$ & $-0,069$ & 0,015 \\
\hline Open & $\begin{array}{l}- \\
0,031 * *\end{array}$ & $-0,026$ & $-0,011$ & $-0,0001$ & $-0,010$ & open & $\begin{array}{l}- \\
0,023 * *\end{array}$ & $\begin{array}{l}- \\
0,020 *\end{array}$ & $-0,015$ & 0,00002 & $0,011^{* *}$ \\
\hline Educul & $-0,007$ & $-0,0003$ & 0,0013 & $0,007 * *$ & $0,011^{* * *}$ & educul & $-0,008$ & $-0,001$ & $-0,001$ & 0,005 & $0,012^{* *}$ \\
\hline Sausan & $-0,049^{*}$ & $-0,033^{*}$ & $-0,007$ & $0,022^{* * *}$ & $-0,005$ & sausan & $0,052^{* * *}$ & $\begin{array}{l}- \\
0,040 *\end{array}$ & - $0,031 * *$ & $-0,031^{*}$ & 0,003 \\
\hline Júri & $0,0533^{*}$ & $0,027^{*}$ & 0,0012 & $0,019 * *$ & 0,004 & júri & 0,028 & $0,032 *$ & 0,0131 & $0,030^{*}$ & 0,003 \\
\hline NivSB2 & $-0,069^{*}$ & $\begin{array}{l}- \\
0,032 * *\end{array}$ & $-0,025$ & 0,008 & 0,0227 & EficSB & $-0,097^{*}$ & $\begin{array}{l}- \\
0,080 *\end{array}$ & $-0,094^{*}$ & $-0,094^{*}$ & $-0,078^{*}$ \\
\hline Pseudo $R^{2}$ & 0,93 & 0,92 & 0,91 & 0,91 & 0,90 & $\begin{array}{l}\text { Pseudo } \\
R^{2}\end{array}$ & 0,93 & 0,92 & 0,91 & 0,91 & 0,91 \\
\hline
\end{tabular}

Fonte: Elaboração própria.

Nota: * significante ao nível de 1\%; ** significante ao nível de 5\%; *** significante ao nível de 10\%.

Os resultados apresentados na Tabela 5 buscam captar o argumento pós-keynesiano em relação ao impacto da PLP e da PLB sobre o nível de renda. Para tanto, seguiu-se a mesma metodologia anterior. A hipótese teórica é que, quanto maior forem a PLP e a PLB, menor será a oferta de crédito e, portanto, menor será o crescimento econômico. Assim, em termos econométricos, os coeficientes esperados devem apresentar sinal negativo e exibir magnitude decrescente dos primeiros para os últimos quantis.

Tabela 5 - Resultados das regressões quantilicas para a PLB e a PLP

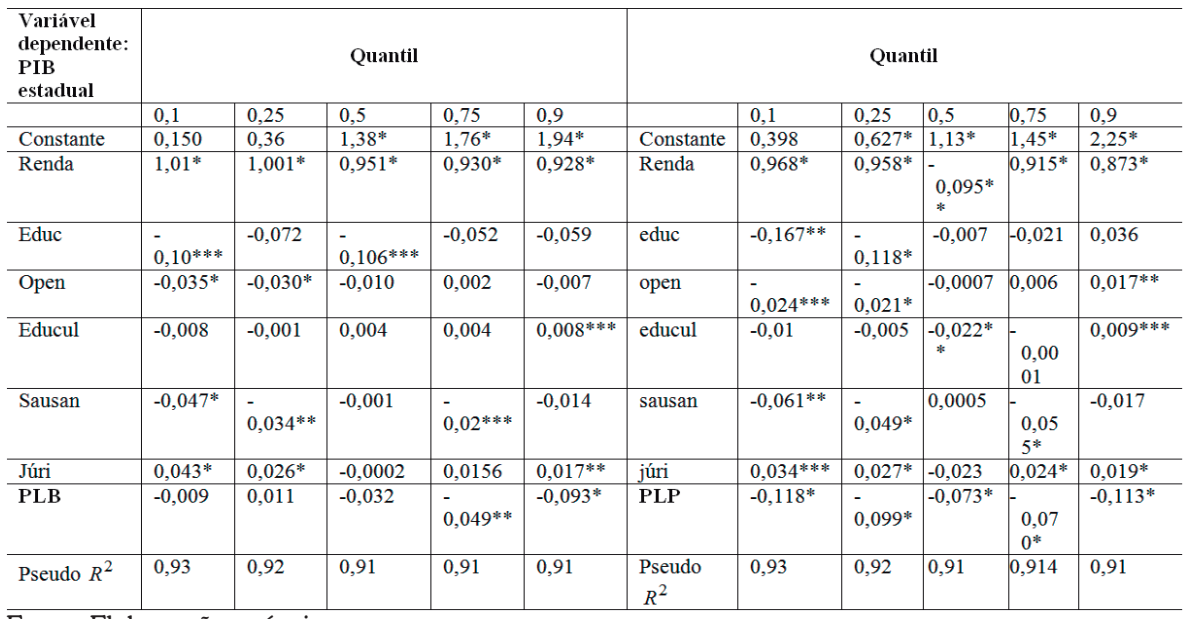

Fonte: Elaboração própria.

Nota: " significante ao nível de 1\%; "* significante ao nível de 5\%; "** significante ao nível de 10\%. 
O indicador de PLP exibe o comportamento esperado, uma vez que o sinal dos coeficientes foi negativo e estatisticamente significativo a 1\%. Na variável magnitude exibiram um comportamento decrescente, com exceção do último quantil. O coeficiente associado ao indicador de PLB também apresentou o sinal esperado (negativo), embora tenha sido estatisticamente significativo (5\%) somente para os dois quantis superiores do nível de renda. Em suma, as evidências encontradas parecem corroborar o argumento pós-keynesiano.

Por fim, utilizando a subamostra para os quais os dados para a proxy de tecnologia estão disponíveis, foram feitos os mesmos exercícios econométricos anteriores. Os resultados (não reportados) por $\mathrm{MQO}$ são semelhantes, com exceção dos indicadores do nível de atividade do sistema bancário. O primeiro indicador tornou-se estatisticamente significativo, mantendo o sinal positivo, enquanto o segundo indicador inverteu o sinal de negativo para positivo, embora continue não significativo.

Do ponto de vista das regressões quantílicas, os resultados também tendem a se manter. No que tange aos indicadores de desenvolvimento do sistema financeiro, as mudanças ocorridas são: para o indicador de tamanho de mercado, os coeficientes significativos passam a ser aqueles associados ao segundo e ao terceiro quantil estimados, mantendo o sinal positivo; para o indicador nível de atividade (1), a mudança de sinal ao longo da distribuição permanece, mas agora os coeficientes significativos (todos com sinal positivo) são o terceiro, quarto e quinto quantil, enquanto o indicador nível de atividade (2) se torna não significativo ao longo de toda distribuição; o indicador de PLP tem o sinal esperado ao longo de toda a distribuição, mas é estatisticamente significante somente nos dois quantis inferiores de renda; e o indicador de PLB tem o sinal esperado, tornando-se estatisticamente significativo também para o terceiro quantil de renda estimado.

A Tabela 6 apresenta o teste de Wald para a diferença entre os coeficientes. Mais especificamente, testamos se os coeficientes associados ao primeiro e ao segundo quantil são estatisticamente diferentes dos coeficientes do último quantil. 
Tabela 6 - Teste de Wald para a diferença entre os coeficientes

\begin{tabular}{|c|c|c|}
\hline \multirow{2}{*}{ Indicador } & \multicolumn{2}{|c|}{ Hipóteses } \\
\hline & {$[q 10]-[q 90]=0$} & {$[q 25]-[q 90]=0$} \\
\hline depvista & $\begin{array}{c}F(19,249)=133.83 \\
\text { Prob }>F=0.0000\end{array}$ & $\begin{array}{c}F(19,249)=5.61 \\
\text { Prob }>F=0.0000\end{array}$ \\
\hline deprazo & $\begin{array}{c}F(19, \quad 249)=9.99 \\
\text { Prob }>F=0.0000\end{array}$ & $\begin{array}{c}F(19, \quad 249)=434.31 \\
\text { Prob }>F=0.0000\end{array}$ \\
\hline TamSB & $\begin{array}{c}F(19, \quad 249)=8.01 \\
\text { Prob }>F=0.0000\end{array}$ & $\begin{array}{c}F(19, \quad 249)=286.82 \\
\text { Prob }>F=0.0000\end{array}$ \\
\hline NivSB1 & $\begin{array}{c}F(19, \quad 249)=174.75 \\
\text { Prob }>F=0.0000\end{array}$ & $\begin{array}{c}F(19,249)=23.81 \\
\text { Prob }>F=0.0000\end{array}$ \\
\hline NivSB2 & $\begin{array}{c}F(19,249)=289.20 \\
\text { Prob }>F=0.0000\end{array}$ & $\begin{array}{c}F(19,249)=92.55 \\
\text { Prob }>F=0.0000\end{array}$ \\
\hline EficSB & $\begin{array}{c}F(19, \quad 249)=673.75 \\
\text { Prob }>F=0.0000\end{array}$ & $\begin{array}{c}F(19, \quad 249)=375.02 \\
\text { Prob }>F=0.0000\end{array}$ \\
\hline PLB & $\begin{array}{c}F(19, \quad 249)=99.44 \\
\text { Prob }>F=0.0000\end{array}$ & $\begin{array}{c}F(19, \quad 249)=13.97 \\
\text { Prob }>F=0.0000\end{array}$ \\
\hline PLP & $\begin{array}{c}\mathrm{F}(19, \quad 249)=22.89 \\
\text { Prob }>\mathrm{F}=0.0000\end{array}$ & $\begin{array}{c}\mathrm{F}(19, \quad 249)=48.85 \\
\text { Prob }>\mathrm{F}=0.0000\end{array}$ \\
\hline
\end{tabular}

Fonte: Elaboração própria.

Nota: Testa-se conjuntamente se [qx1]renda - [qx2]renda =0; [qx1]educ - [qx2]educ $=0$; [qx1]

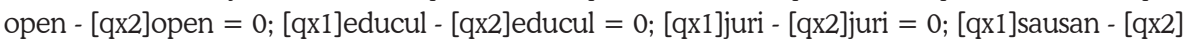
sausan $=0$ e $[\mathrm{qx} 1]$ deprazo $-[\mathrm{qx} 2]$ deprazo $=0$, em que $\mathrm{x} 1 \mathrm{e}$ x2 referem-se ao nível inferior e superior do quantil, respectivamente.

Os resultados mostram que não podemos rejeitar a hipótese de que os coeficientes são estatisticamente diferentes. Isso implica que os parâmetros mudam ao longo da distribuição, levando a crer que a análise deve levar em consideração a influência assimétrica que o desenvolvimento do sistema financeiro tem sobre as diferentes unidades federativas do Brasil.

\section{Considerações Finais}

Este trabalho analisa empiricamente, para as unidades federativas brasileiras, a relação entre desenvolvimento financeiro e crescimento econômico, utilizando regressão quantílica. Os resultados sugerem uma relação positiva entre essas variáveis.

Para mensurar o desenvolvimento do sistema financeiro foram adotadas duas estratégias: a primeira inspirou-se no trabalho de King e Levine (1993b), que define algumas variáveis financeiras como indicadoras de desenvolvimento desse sistema. A relação encontrada foi positiva (e significativa) para ambos os indicadores (depvista e deprazo). A segunda estratégia consistiu na construção de alguns indicadores para tamanho, nível e eficiência do sistema financeiro. As evidências confirmam a relação anterior, com exceção do indicador de eficiência. Além disso, deve-se ressaltar que esses últimos indicadores indicam a existência de uma relação negativa entre o desenvolvimento do sistema financeiro e o nível de renda 
para as unidades federativas menos desenvolvidas, o que pode significar uma não funcionalidade desse sistema, que agrava as disparidades de renda regional.

Em termos de política econômica, os resultados encontrados sugerem que o desenvolvimento do sistema financeiro deve ser estimulado, mas é preciso tomar certas precauções, sobretudo porque as regiões mais remotas (menos desenvolvidas) podem ser prejudicadas. Nesse sentido, abre-se espaço para políticas públicas, ou, mais especificamente, para a intervenção do Estado, seja através de políticas específicas, como o caso da Superintendência do Desenvolvimento do Nordeste (Sudene), criada por Celso Furtado, ou de políticas direcionadas pelos bancos públicos estatais no sentido de gerar linhas de crédito específicas para essas regiões, por exemplo. Obviamente, os resultados também retomam a discussão sobre a necessidade de que, dado que o sistema financeiro é um importante instrumento de desenvolvimento econômico, o governo seja mais do que apenas um órgão regulador, mantendo uma participação ativa nessa atividade econômica via representativa participação acionária junto aos bancos privados e/ou via bancos públicos estatais. A experiência brasileira atual e diante da crise financeira internacional de 2007-2008 mostra a importância da atuação dessas instituições na geração de crédito e na redução dos spreeds bancários.

Por outro lado, os resultados também sugerem a necessidade de se desenhar mecanismos de política econômica que levem em consideração as características de cada região, pois nesse caso é possível amenizar a tendência de concentração (polos) da atividade financeira (como o caso de São Paulo, por exemplo). Ou seja, os resultados sugerem que a gestão dos ativos bancários no espaço (diferente preferência pela liquidez) acaba por desempenhar um papel ativo na configuração das diferenças inter-regionais brasileiras.

Por fim, do ponto de vista econométrico, é possível que as estimativas tenham incorrido em algum problema, sobretudo os advindos da endogeneidade pela ausência de controles diretos para a tecnologia e instituições. No primeiro caso, a introdução de variável proxy para tecnologia mostrou-se significativa, embora não tenha alterado os resultados. Assim, apesar de mudar a magnitude dos coeficientes, seu sinal continuou o mesmo, sugerindo que esse problema pode não invalidar os resultados alcançados. Infelizmente, não existem dados sobre essa variável que possam suprir essa lacuna, embora algum esforço tenha sido empregado recentemente nesse sentido, principalmente a partir da Pesquisa de Inovação Tecnológica (Pintec) do IBGE. No entanto, os dados dessa pesquisa ainda são insuficientes para uma análise mais elaborada. Com relação à variável instituições, sugere-se como desafio para pesquisas futuras se encontrar um melhor instrumento ou proxy capaz de qualificar a análise. 


\section{Referências}

ACEMOGLU, D. Introduction to modern economic growth. Princeton: University Press, 2009.

ACEMOGLU, D.; JOHNSON, S.; ROBINSON, S. Institutions as a fundamental cause of longrun growth. In: AGHION, P.; DURLAUF, S. N. (Ed.). Handbook of Economic Growth. North Holland: Elsevier, 2005, p. 385-472

ALMEIDA, D. C.; JAYME JR, F. G. Bank consolidation and credit concentration in Brazil. CEPAL Review, v. 95, n. 2, p. 157-173, Aug. 2008.

ARAÚJO, E. C.; DIAS, J. Endogeneidade do setor financeiro e crescimento econômico: uma análise empírica para a economia brasileira (1980 a 2003). Revista Economia Contemporânea, v. 10, n. 3, p. 575-609, set./dez 2006.

ARESTIS, P.; CHORTAREAS, G.; DESLI, E. Financial development and productive efficiency in OECD countries: an explanatory analysis. The Manchester School of Economic and Social Research, v. 74, n. 4, p. 417-440, July 2006.

ARESTIS, P.; DEMETRIADES, P. Finance and growth: is Schumpeter right? Análise Econômica, v. 6, n. 30, p. 5-21, 1998.

ARRAES, R. A.; TELES, V. K. Endogeneidade e exogeneidade do crescimento econômico: uma análise comparativa entre Nordeste, Brasil e países selecionados. Revista Econômica do Nordeste, v. 31, n. especial, p. 754-776, 2000.

AZZONI, C. R. Concentração regional e dispersão das rendas per capita estaduais: análise a partir de séries históricas estaduais de PIB, 1939-1995. Estudos Econômicos, v. 30, n. 2, p. 207-231, abr.jun. 1997.

BARRA, C.; CROCCO, M. Moeda e espaço no Brasil: um estudo de áreas selecionadas. Revista de Economia Política, v. 24, n. 3(95), p. 386-406, jul./set. 2004.

BARRO, R. Health and economic growth,. Cambridge, MA: Harvard University, 1996. Mimeo.

BARRO, R.; SALA-I-MARTIN, X. Economic growth. New York: McGraw-Hill, 1995.

BECK, T.; LEVINE, R; LOAYZA, N. Finance and sources of growth. Journal of Financial Economics. v. 58. n. 1-2, p. 261-300, Special Issue, 2000.

BLOOM, D. E; CANNING, D.; SEVILLA, J. The effect of health on economic growth: theory and evidence. Cambridge: NBER, Nov. 2001. (Working Paper, n. 8.587)

CARVALHO, F. C. Sobre a centralidade da teoria da preferência pela liquidez na macroeconomia pós-keynesiana. Ensaios FEE, Porto Alegre, v. 17, n. 2, p. 42-77, 1996.

CAVALCANTE, A. Regional financial development and economic growth. 2011. $234 \mathrm{f}$. Dissertation (Doctor of Philosophy) - University of Cambridge, Cambridge, 2011.

CAVALCANTE, A.; CROCCO, M.; JAYME JR., F. Preferência pela liquidez, sistema bancário e disponibilidade de crédito regional, In: CROCCO, M.; JAYME JR., F. (Org.) Moeda e 
território: uma interpretação da dinâmica regional brasileira. Belo Horizonte: Autêntica, 2006. p. 295-315.

CHICK, V. The evolution of the banking system and the theory of saving, investment and interest. In: ARESTIS, P.; DOW, S. C. (Ed.). On money, method and Keynes. New York: St. Martin's Press, 1992. p. 193-205.

CONCEIÇÃO, O. A. C. Instituições, crescimento e mudança na ótica institucionalista. 2000. 228p. Tese (Doutorado em Economia) - Programa de Pós-Graduação em Economia, Faculdade de Ciências Econômicas, Universidade Federal do Rio Grande do Sul, Porto Alegre, 2000.

CROCCO, M.; CAVALCANTE, A.; CASTRO, C. The behaviour of liquidity preference of banks and public and regional development: the case of Brazil. Journal of Post Keynesian Economics, v. 28, n. 2, p. 217-40, 2005.

CROCCO, M.; FIGUEIREDO, A.; SANTOS, F. Differentiated banking strategies across the territory: an exploratory analysis. Journal of Post Keynesian Economics, v. 33, n. 1, p. 127-150, Fall 2010.

CROCCO, M.; SANTOS, F.; AMARAL, P. The spatial structure of the financial development in Brazil. Spatial Economic Analysis, v. 5, n. 181-203, p. 181-293, Dec. 2010.

DARRAT, A. F. Are financial deepening and economic growth causality related? Another look at the evidence. International Economic Journal, v. 13, n. 3, p. 19-35, 1999.

DINIZ, C. Desenvolvimento poligonal no Brasil: nem desconcentração nem contínua polarização. Revista Nova Economia, Belo Horizonte, v. 3, n. 1, p. 35-64, Set.1993.

DOW, S. C. The regional financial sector: a Scottish case study. Regional Studies, v. 26, n. 7 , p. 619-631, 1992.

FRY, M. J. Money, interest and banking in economic development. 2. ed. Baltimore and London: The Johns Hopkins University Press, 1995.

FURTADO, C. Desenvolvimento e subdesenvolvimento. Rio de Janeiro: Fundo de Cultura, 1959.

FURTADO, C. Subdesenvolvimento e estagnação na América Latina. Rio de Janeiro: Civilização Brasileira, 1966.

GALEANO, E.; FEIJO, C. A. Crédito e crescimento econômico: evidências a partir de um painel de dados regionais para a economia brasileira nos anos 2000. Niterói: Center for Studies on Inequality and Development, Mar. 2011. (Discussion Paper, n. 32).

GELB, A. H. Financial policies, growth, and efficiency. Washington: World Bank, June 1989. (Working Papers, n. 202).

GOLDSMITH, R. Financial structure and development. New Haven and London: Yale University Press, 1969. 
GONÇALVES, A. C. P. Crescimento econômico e setor financeiro no Brasil. Pesquisa e Planejamento Econômico, v. 10, n. 3, p. 955-970, Dez. 1980.

GRAFF, M. Casual links between financial activity and economic growth: empirical evidence from a cross-country analysis, 1970-1990. Bulletin of Economic Research, v. 54, n. 2, p.119133, Apr. 2002.

GURLEY, J. G.; SHAW, E. Financial aspects of economic development. American Economic Review. v. 45, n. 4, p. 515-538, Sept. 1955.

HERMANN, J. O modelo de liberalização financeira dos anos 1990: restatement ou autocrítica? Nova Economia, v. 13, n. 2, p. 137-172, Jul./Dec. 2003.

HIRSCHMAN, A. Ascensão e declínio da economia do desenvolvimento. Revista de Ciências Sociais, Rio de Janeiro, v. 25, n. 1, p. 5-2, 1982.

. O. Estratégia do desenvolvimento econômico. Rio de Janeiro: Fundo de Cultura, 1961. Publicado originalmente em 1958.

HODGSON, G. M. How economics forgot history: the problem of historical specificity in social science. London and New York: Routledge, 2001.

. The hidden persuaders: institutions and individuals in economic theory. Cambridge Journal of Economics, v. 27, n. 2, p. 159-175, 2003.

KEYNES, J. M. A teoria geral do emprego, do juro e do dinheiro. São Paulo, abril cultural, [1936] 1983.

. The 'ex-ante' theory of the rate of interest. In: MOGGRIDGE, D. (Ed.). The collected writings of John Maynard Keynes. London: MacMillan, 1973. v. XIII.

KING, R.; LEVINE, R. Finance and growth: Schumpeter might be right. Quartely Journal of Economics, v. 108, n 3, p. 717-737, Aug.1993b.

Finance, entrepreneurship and growth: theory and evidence. Journal of Monetary Economics, v. 32, n. 3, p. 513-542, Dec. 1993c.

KING, R.; LEVINE, R. Financial intermediation and economic development. In: MAYER, C.; VIVES, X. (Ed.). Financial intermediation in the construction of Europe. London: Center for Economic Policy Research, 1993a. p. 156-189.

KOENKER, R.; BASSETT, G. Regression quantiles. Econometrica, Chicago, v. 46, n. 1, p. 3350, Jan. 1978.

. Robust test for heteroscedasticity based on regression quantiles. Econometrica, v. 50, n. 1, Jan. 1982.

KOENKER, R.; HALLOCK, K. Quantile regression. Journal of Economic Perspectives, Nashville, v. 15, n. 4, p. 143-156, Fall 2001.

KROTH, D. C.; DIAS, J. A contribuição do crédito bancário e do capital humano no crescimento econômico dos municípios brasileiros: uma análise em painéis de dados 
dinâmicos. In: ENCONTRO NACIONAL DE ECONOMIA, 34, 2006, Salvador. Anais... Salvador: Anpec, 2006.

LA PORTA, R. et al. Law and finance. Journal of Political Economy, v. 106, n. 6, p. 1113-1155, Dec. 1998.

LEVINE, R. Financial development and economic growth: Views and agenda. Journal of Economic Literature. v. 35, n. 2, p. 688-726, June 1997.

. Law, finance, and economic growth. Journal of Financial Intermediation, v. 8, n. 1-2, p. 8-35, January 1999.

Stock markets: a spur to economic growth. Finance and Development, v. 33, n. 1, p. 7-10, Mar. 1996.

. The legal environment, banks, and long-run economic growth, Journal of Money, Credit, and Banking, v. 30, n. 3, p. 596-613, 1998.

LEVINE, R.; ZERVOS. S. Stock market banks and economic growth. American Economic Review, v. 88, n. 3, p. 323-339, Jun.1998.

LUCAS, R. On the mechanics of economic development. Journal of Monetary Economics. v. 22, p. 3-42, 1988.

MANKIW, N. G.; ROMER, D.; WEIL, D. A contribution to the empirics of economic growth. Quarterly Journal of Economics, Cambridge, v. 107, n. 2, p. 407-437, May 1992.

MARQUES JR., T. E.; PORTO JR., S. S. Desenvolvimento financeiro e crescimento econômico no Brasil: Uma avaliação econométrica. Porto Alegre: PPGE/UFRGS, 2004, (Trabalho para Discussão, n. 11).

MARX, K. O Capital. Rio de Janeiro: Civilização Brasileira, 1968.

MATOS, O. C. Desenvolvimento do sistema financeiro e crescimento econômico no Brasil: Evidência de causalidade. Brasília, DF: Banco Central do Brasil, Set. 2002. (Trabalho para Discussão, n. 49).

MONTE, P. A.; TÁVORA JÚNIOR, J. L. Fontes de financiamento do Nordeste e o produto interno bruto da região. Revista Econômica do Nordeste, v. 31, n. especial, p. 676-695, nov. 2000 .

NARITOMI, J. Herança colonial, instituições e desenvolvimento: um estudo sobre a desigualdade entre os municípios brasileiros. 2007. Dissertação (Mestrado em Economia), Programa de Pós-Graduação em Economia, Pontifícia Universidade Católica do Rio de Janeiro, Rio de Janeiro, 2007.

NOGUEIRA, M.; FIGUEIREDO, A. T. L.; CROCCO, M.. Gestão de Ativo bancário diferenciada no território: um estudo pra os estados brasileiros. In: ENCONTRO NACIONAL DE ECONOMIA, 36., 2008, Salvador. Anais... Salvador: Anpec, 2008. 
OREIRO, J. L. C. Equilíbrio temporário, taxa de juros e o motivo finanças de demanda por moeda: uma reavaliação da teoria da preferência pela liquidez. Estudos Econômicos, São Paulo, v. 28, n. 1, p. 579-600, Out/ Dez. 1998a.

. Preferência pela liquidez e escolha de portfólio. Análise Econômica, Porto Alegre, v. 17, n. 32, p. 87-108, Setembro 1999.

PAULA, L. F. Dinâmica da firma bancária: uma abordagem não-convencional. Revista Brasileira de Economia, v. 53, n. 3, p. 323-356, 1999.

. Financiamento, crescimento econômico e funcionalidade do sistema financeiro: uma abordagem pós-keynesiana. Estudos Econômicos, São Paulo, v. 43, n. 2, p. 363-396, Apr./June 2013.

PIRES, M. C. C. Crédito e crescimento econômico: evidências para os municípios brasileiros. In: ENCONTRO DE ECONOMIA DA REGIÃO SUL, 13, 2005, Porto Alegre, Anais... Porto Alegre: ANPEC-SUL, 2005.

REBELO, S. Long-run policy analysis and long-run growth. Journal of Political Economy, v. 99, n. 3, p. 500-521, Jun. 1991.

RESENDE, M. F. C. O circuito finance-investimento-poupança-funding em economias abertas. Revista de Economia Politica, v. 28, n 1(109), p. 136-154, jan.-mar. 2007.

ROCHA, B. de P.; NAKANE, M. I. Sistema financeiro e desenvolvimento econômico: evidências de causalidade em um painel para o Brasil. In: ENCONTRO NACIONAL DE ECONOMIA, 35., 2007, Recife, Anais... Recife: Anpec, 2007.

ROMER, P. M. Increasing returns and long-run growth. Journal of Political Economics, v. 94, n. 5, p. 1000-1037, Oct. 1986.

ROUSSEAU, P. L.; WACHTEL, P. Financial intermediation and economic performance: historical evidence from five industrialized countries. Journal of Money, Credit, and Banking. v. 30, n. 4, p. 657-678, Nov. 1998.

SHAW, E. S. Financial deepning in economic development. New York: Oxford University Press, 1973.

SILVA, E. N.; PORTO JR., S. S. Sistema financeiro e crescimento econômico: uma aplicação de regressão quantílica. Revista Economia Aplicada, São Paulo, v. 10, n. 3, p. 425-442, 2006.

SOLOW, R. M. A Contribution to the Theory of Economic Growth. The Quarterly Journal of Economics, Vol. 70, No. 1, pp. 65-94, Feb. 1956.

STIGLITZ, J. E.; WEISS, A. Credit rationing with imperfect information. American Economic Review. v. 71, n. 3, p. 393-410, Jun.1981.

STUDART, R. O sistema financeiro e o financiamento do crescimento: uma alternativa póskeynesiana à visão convencional. Revista de Economia Política, v. 13, n. 1(49), p. 101-118, jan./mar. 1993.

STUDART, R.. Investment finance in economic development. London: Routledge, 1995. 
TRINER, G. D. Banking, economic growth and industrialization: Brazil, 1906-30. Revista Brasileira de Economia, v. 50, n. 1, p. 135-153, jan./mar.1996.

ZARA, T. M. Desenvolvimento financeiro, crescimento e desigualdade nos estados brasileiros. 54 f. 2006. Dissertação (Mestrado em Teoria Econômica) - Departamento de Economia, Faculdade de Economia, Administração e Contabilidade, Universidade de São Paulo, São Paulo, 2006.

Recebido em: 26/04/2013. Aceito em: 02/08/2013. 